\title{
Intervention for arch obstruction after the Norwood procedure: Prevalence, associated factors, and practice variability
}

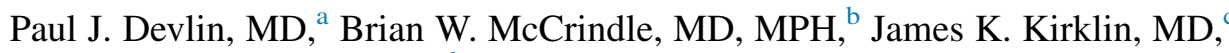
Eugene H. Blackstone, MD, ${ }^{\mathrm{d}}$ William M. DeCampli, MD, PhD, ${ }^{\mathrm{e}}$ Christopher A. Caldarone, MD, ${ }^{\mathrm{f}}$ Ali Dodge-Khatami, MD, PhD, ${ }^{g}$ Pirooz Eghtesady, MD, PhD, ${ }^{h}$ James M. Meza, MD, MSc, ${ }^{\mathrm{i}}$ Peter J. Gruber, MD, PhD, ${ }^{\mathrm{j}}$ Kristine J. Guleserian, MD, ${ }^{\mathrm{k}}$ Bahaaladin Alsoufi, MD, Linda M. Lambert, MSN-cFNP, ${ }^{\mathrm{m}}$ James E. O'Brien, Jr, MD, ${ }^{\mathrm{n}}$ Erle H. Austin III, MD, ${ }^{1}$ Jeffrey P. Jacobs, MD, ${ }^{\circ}$ and Tara Karamlou, MD, $\mathrm{MSc}^{\mathrm{p}}$

\section{ABSTRACT}

Objective: Arch obstruction after the Norwood procedure is common and contributes to mortality. We determined the prevalence, associated factors, and practice variability of arch reintervention and assessed whether arch reintervention is associated with mortality.

Methods: From 2005 to 2017, 593 neonates in the Congenital Heart Surgeons' Society Critical Left Heart Obstruction cohort underwent a Norwood procedure. Median follow-up was 3.7 years. Multivariable parametric models, including a modulated renewal analysis, were performed.

Results: Of the 593 neonates, 146 (25\%) underwent 218 reinterventions for arch obstruction after the Norwood procedure: catheter-based $(n=168)$ or surgical $(\mathrm{n}=50)$ at a median age of 4.3 months (quartile 1-quartile 3, 2.6-5.7). Interdigitation of the distal aortic anastomosis was protective against arch reintervention. Development of $\geq$ moderate tricuspid valve regurgitation and right ventricular dysfunction at any point was associated with arch reintervention. Nonsignificant variables for arch reintervention included shunt type and preoperative aortic measurements. Surgical arch reintervention was protective against arch reintervention, but transcatheter reintervention was associated with increased reintervention. Arch reintervention was not associated with increased mortality. There was wide institutional variation in incidence of arch reintervention (range, 0-40 reinterventions per 100 years patient follow-up) and in preintervention gradient (range, 0-64 $\mathrm{mm} \mathrm{Hg}$ ).

Conclusions: Interdigitation of the distal aortic anastomosis during the Norwood procedure decreased the risk of arch reintervention. Surgical arch reintervention is

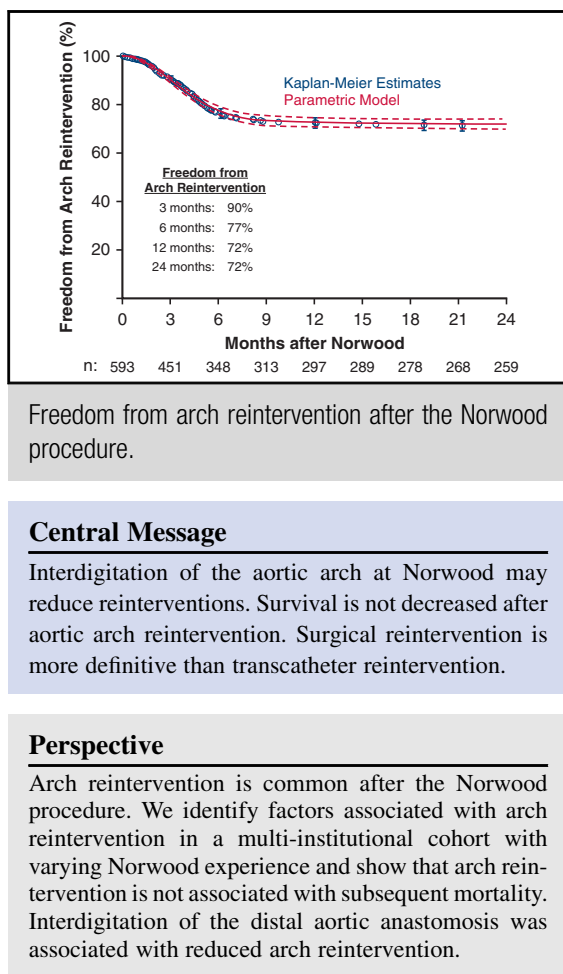

See Editorial Commentary page 696

\footnotetext{
From the ${ }^{\mathrm{a}}$ Division of Cardiovascular Surgery, and ${ }^{\mathrm{b}}$ Division of Pediatric Cardiology, The Hospital for Sick Children, Toronto, Ontario, Canada; ${ }^{\circ}$ Division of Cardiothoracic Surgery, University of Alabama at Birmingham, Birmingham, Ala; ${ }^{\mathrm{d} D i v i s i o n}$ of Thoracic and Cardiovascular Surgery and Quantitative Health Sciences, Cleveland Clinic, Cleveland, Ohio; ' ${ }^{\mathrm{e} D i v i s i o n}$ of Pediatric Cardiac Surgery, Arnold Palmer Hospital for Children, Orlando, Fla; ${ }^{\mathrm{f}}$ Department of Cardiovascular Surgery, Baylor College of Medicine, Houston, Tex; ${ }^{\mathrm{g}}$ Division of Pediatric Cardiac Surgery, The University of Mississippi Medical Center, Jackson, Miss; ${ }^{\mathrm{h}}$ Department of Pediatric Cardiothoracic Surgery, Washington University Medical School,

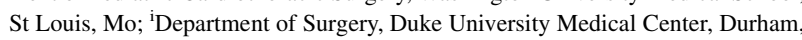
NC; ${ }^{j}$ Department of Surgery, Yale University School of Medicine, New Haven, Conn; ${ }^{\mathrm{k}}$ Division of Cardiovascular Surgery, Nicklaus Children's Hospital, Miami, Fla; ${ }^{\mathrm{l} C a r d i o v a s c u l a r}$ Surgery, Norton Children's Hospital, University of Louisville, Louisville, Ky; ${ }^{\mathrm{m}}$ Department of Pediatrics, Primary Children's Hospital, Salt Lake

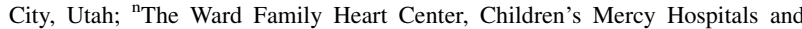
Clinics, Kansas City, Mo; ${ }^{\circ}$ Division of Cardiovascular Surgery, Johns Hopkins
}

All Children's Hospital, St Petersburg, Fla; and ${ }^{\mathrm{P}}$ Division of Pediatric Cardiac Surgery, Rady Children's Hospital, San Diego, Calif.

Funding for Dr. Devlin was provided by the Congenital Heart Surgeons' Society John W. Kirklin/David Ashburn Fellowship, the Hospital for Sick Children Division of Cardiovascular Surgery, and the Ann \& Robert H. Lurie Children's Hospital of Chicago Division of Cardiovascular-Thoracic Surgery. The Congenital Heart Surgeons' Society Data Center is supported financially by all Congenital Heart Surgeons' Society institutional members.

Read at the 98th Annual Meeting of The American Association for Thoracic Surgery, San Diego, California, April 28-May 1, 2018.

Received for publication April 29, 2018; revisions received Aug 28, 2018; accepted for publication Sept 12, 2018.

Address for reprints: Paul J. Devlin, MD, 555 University Ave, Rm 4431, Toronto, Ontario M5G 1X8, Canada (E-mail: paul.devlin@sickkids.ca).

$0022-5223 / \$ 36.00$

Copyright () 2018 by The American Association for Thoracic Surgery

https://doi.org/10.1016/j.jtcvs.2018.09.130 
Abbreviations and Acronyms

CHSS $=$ Congenital Heart Surgeons' Society

SVR $=$ Single Ventricle Reconstruction

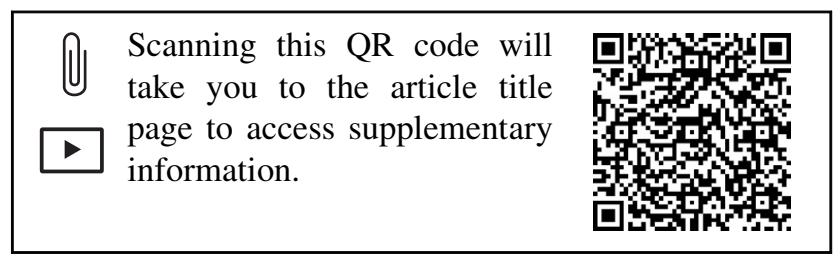

more definitive than transcatheter. Arch reintervention after the Norwood procedure is not associated with increased mortality. Serial surveillance for arch obstruction, integrated with changes in right ventricular function and tricuspid valve regurgitation, is recommended after the Norwood procedure to improve outcomes. (J Thorac Cardiovasc Surg 2019;157:684-95)

Arch obstruction after the Norwood procedure causes mortality. ${ }^{1}$ However, prevalence of arch obstruction is difficult to assess accurately because of a lack of a standardized definition, differences in gradient assessed using echocardiography and catheterization, and high rate of post-Norwood procedure deaths without an identified cause. Therefore, we studied the occurrence of arch interventions to assess the effect of, and factors associated with, aortic reintervention after the Norwood procedure.

The reported prevalence of arch reintervention after the Norwood procedure ranges from $0 \%$ to $46 \%$ depending on institution and subsets of surgical technique. ${ }^{2-13} \mathrm{An}$ analysis of the Single Ventricle Reconstruction (SVR) trial data set has identified higher Norwood procedure discharge arch gradient and presence of a right ventricle to pulmonary artery conduit as risk factors for arch reintervention after the Norwood procedure..$^{10}$ Conditional survival analyses have shown that survival in patients after arch reintervention is equivalent to survival in those who do not undergo reintervention. ${ }^{7,10,14}$

Using the Congenital Heart Surgeons' Society (CHSS) multi-institutional critical left heart obstruction cohort, we determined the prevalence of, and associated factors for, arch reintervention after the Norwood procedure and analyzed the relationship between arch reintervention and death.

\section{METHODS}

This study was approved on January 14, 2005, by the Hospital for Sick Children Research Ethics Board (REB) (REB number: 1000006372). The study expiration date is January 23, 2019.
From March 2005 to November 2017, neonates with critical left heart obstruction were enrolled prospectively with the CHSS from 27 institutions (Table E1). Critical left heart obstruction was defined as the morphologic spectrum of left heart anomalies that resulted in a neonatal ductaldependent systemic circulation, excluding supravalvar aortic stenosis, interrupted aortic arch, or coarctation. Participating institutions obtained institutional review board approval and parental consent. Within this cohort, 593 patients underwent a Norwood procedure and were included in this study. The median age at the time of the Norwood procedure was 6 days. Patient demographic characteristics are shown in Table 1. Before the Norwood procedure, 30 neonates underwent a hybrid procedure, 8 underwent balloon aortic valvuloplasty, 3 underwent surgical aortic valve repair, and 2 underwent stenting of aortic coarctation, all of whom were included in the study.

\section{Data Acquisition}

Data were abstracted from institutional medical records, including detailed operative reports. Preintervention echocardiograms, when available, were evaluated by a blinded single reviewer $(n=458 ; 77 \%)$. Follow-up was obtained via annual clinical updates from participating institutions and through contact with patients' families by the CHSS Data Center to ascertain patients' health status.

\section{Outcome Measures}

Outcome measures included arch reintervention after the Norwood procedure and time-related death. Median follow-up was 3.7 years (quartile 1quartile 3 [Q1-Q3], 0.6-6.9 years). Arch reintervention was defined as a surgical or catheter procedure after the Norwood procedure. Subsequent reinterventions were classified as second, or other ordinal values as appropriate, reinterventions. Death was all-cause mortality after the Norwood procedure.

\section{Patient and Operative Variables}

Patient factors and Norwood procedure operative variables were obtained from clinical records. The proximal aortic anastomosis at the time of the Norwood procedure was classified as either classic, Brawn (no patch), double barrel, modified, reimplantation, or other. With regard to the distal aortic anastomosis, individual anastomosis types and a composite variable for coarctectomy, created on the basis of type of distal aortic anastomosis (aortic transection with end to end, end to side, end to end and medial incision, or interdigitation all were considered complete coarctectomy procedures vs medial incision in the native aorta alone, which did not involve aortic transection) were abstracted. All but 12 patients had an anastomosis that included a patch.

Baseline echocardiographic measurements were obtained by protocolized echocardiographic review by a single reviewer. ${ }^{15}$ Post-Norwood operations, catheter interventions, and echocardiographic measurements of tricuspid regurgitation and right ventricular dysfunction were abstracted from clinical records.

\section{Data Analysis}

Data were analyzed using SAS statistical software (SAS Institute, Cary, NC). Categorical variables were summarized as frequencies with percentages. The normality of all continuous variables was evaluated with the Shapiro-Wilk test. Continuous variables were summarized according to median and quartiles or mean and standard deviation. To identify factors associated with arch reintervention, we performed multivariable parametric hazard analysis. ${ }^{16}$ Because many patients underwent repeated arch reinterventions, we used a modulated renewal process ${ }^{17}$ (Appendix E1). The complete list of variables used in multivariable analysis is provided (Table E2). The constant hazard phase of arch reintervention after the Norwood procedure contained too few events for thorough risk factor analysis. To analyze the association between arch reintervention and mortality, we performed a separate survival analysis using multiphase parametric hazard analysis. Both 
TABLE 1. Descriptive data for the patient $\operatorname{cohort}(n=593)$

\begin{tabular}{|c|c|c|}
\hline Variable & n $(\%)$ & Median (Q1-Q3) \\
\hline \multicolumn{3}{|l|}{ Sex } \\
\hline Male & $385(65)$ & \\
\hline Female & $208(35)$ & \\
\hline \multicolumn{3}{|l|}{ Ethnicity } \\
\hline Asian & $11(2)$ & \\
\hline Black & $39(8)$ & \\
\hline Hispanic & $23(5)$ & \\
\hline White & $403(85)$ & \\
\hline Missing & 117 & \\
\hline \multicolumn{3}{|l|}{ Status } \\
\hline Alive & $403(68)$ & \\
\hline Dead & $190(32)$ & \\
\hline Gestational age, wk & & $39(38-39)$ \\
\hline Norwood age, $\mathrm{d}$ & & $6(4-8)$ \\
\hline Norwood weight, $\mathrm{kg}$ & & $3.1(2.9-3.5)$ \\
\hline \multicolumn{3}{|l|}{ Shunt type } \\
\hline RVPA & $296(50)$ & \\
\hline Modified BT & $294(50)$ & \\
\hline Central & $3(1)$ & \\
\hline
\end{tabular}

Percentages represent the percent of nonmissing values, with a missing category provided when applicable. Q1-Q3, quartile 1-quartile 3; RVPA, right ventriclepulmonary artery; $B T$, Blalock-Taussig.

analyses incorporated time-varying covariables, which included repeated measures of tricuspid valve regurgitation and right ventricular dysfunction on all post-Norwood echocardiograms as well as interval procedures. The echocardiographic time-varying covariables were binary and updated on the basis of severity of $\geq$ moderate with each echocardiogram performed. Interval procedure time-varying covariables included: stage II palliation, Fontan procedure, heart transplantation, single-ventricle to 2-ventricle crossover surgery, tricuspid valve procedures, and arch procedure covariables, detailing type and number of reinterventions.
Variables associated with fewer than 5 events were excluded to reduce the risk of overdetermination. Because only 9 patients in the cohort underwent a Brawn no-patch ascending neoaorta anastomosis, this variable was excluded from the final multivariable risk factor hazard analysis. ${ }^{18}$ Variables with $>50 \%$ missing values were excluded from the analysis. Multiple imputation was performed using PROC MI with the Markov Chain Monte Carlo option for arbitrary missing values. Bootstrap aggregation was used to aid variable selection (500 resamples) ${ }^{19}$ Individual and closely clustered variables that appeared in $>50 \%$ of the bootstrapped models and variables indicating each patient's institution were eligible for selection in the final multivariable risk hazard analysis (Appendix E1). Confidence intervals for predicted survival and freedom from arch reintervention were estimated using the method of statistical differentials. ${ }^{20}$

Variability in arch reintervention practices was analyzed according to institution. Reintervention frequency was quantified per 100 years of patient follow-up. The Pearson correlation coefficient was used to analyze associations between institutional incidence of reintervention and 1 year post-Norwood mortality as well as preintervention gradient for those institutions with at least 3 preintervention catheter gradients available.

\section{RESULTS \\ Prevalence and Features of Arch Interventions After the Norwood Procedure}

Of the 593 infants, 146 (25\%) underwent 218 reinterventions for arch obstruction after the Norwood procedure: catheter $(\mathrm{n}=168)$ or surgical $(\mathrm{n}=50)$ at a median age of 4.3 months (Q1-Q3, 2.6-5.7; Figure 1). Of the catheter procedures, stent placement was performed in $11(7 \%)$ and 24 $(14 \%)$ occurred at pre-stage II catheterization. Of the surgical arch repairs, $29(58 \%)$ occurred concurrently with other surgeries including: stage II procedure $(\mathrm{n}=17)$, heart transplantation $(\mathrm{n}=4)$, biventricular repair $(\mathrm{n}=4)$, Fontan $(\mathrm{n}=2)$, or tricuspid valve repair $(\mathrm{n}=2)$. Within the follow-up interval, 410 patients underwent stage II palliation, 261 underwent Fontan, 31 underwent heart

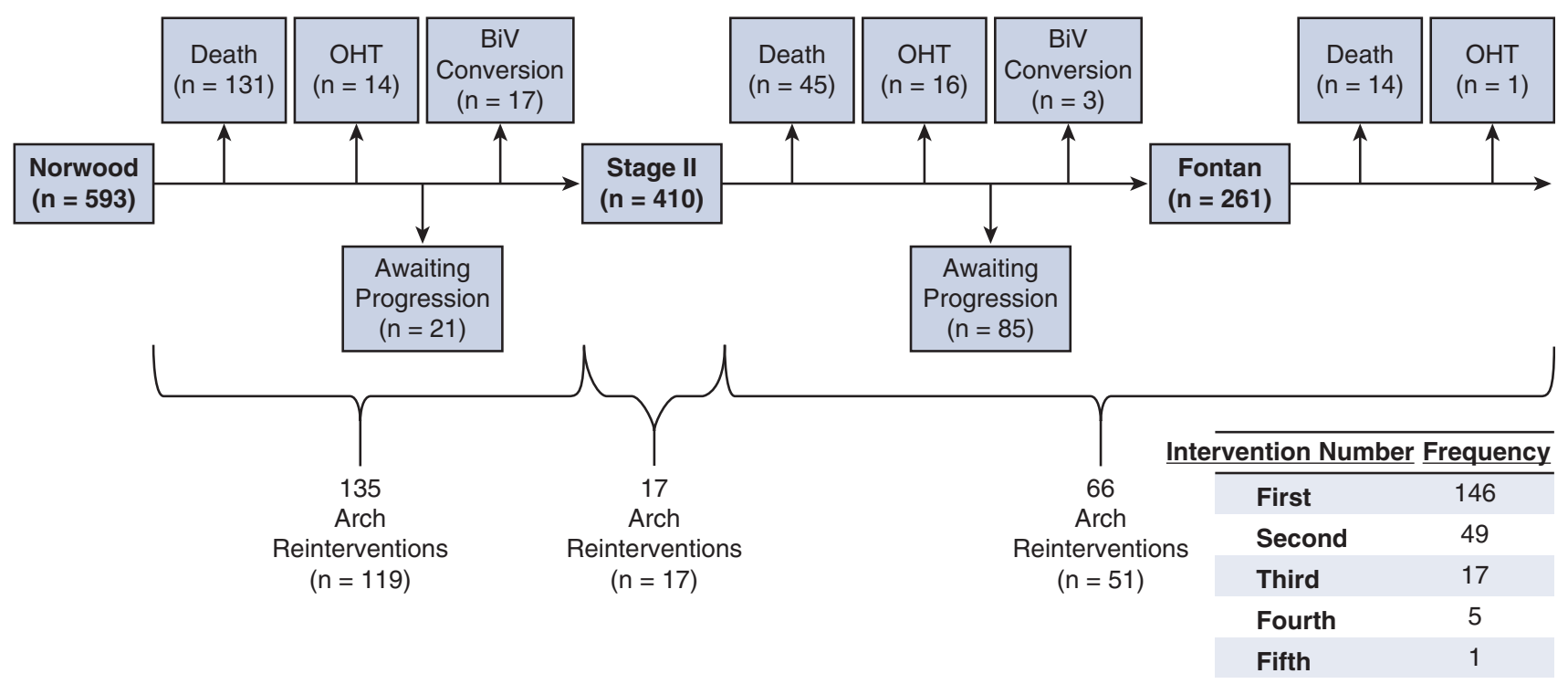

FIGURE 1. Flow chart showing procedures within the analysis cohort $(n=593)$. The distribution of arch reinterventions is shown at the bottom of the figure, with $\mathrm{n}$ representing the number of patients receiving the reinterventions. The inset table shows the frequency of repeated reinterventions. OHT, Orthotopic heart transplantation; BiV, biventricular. 


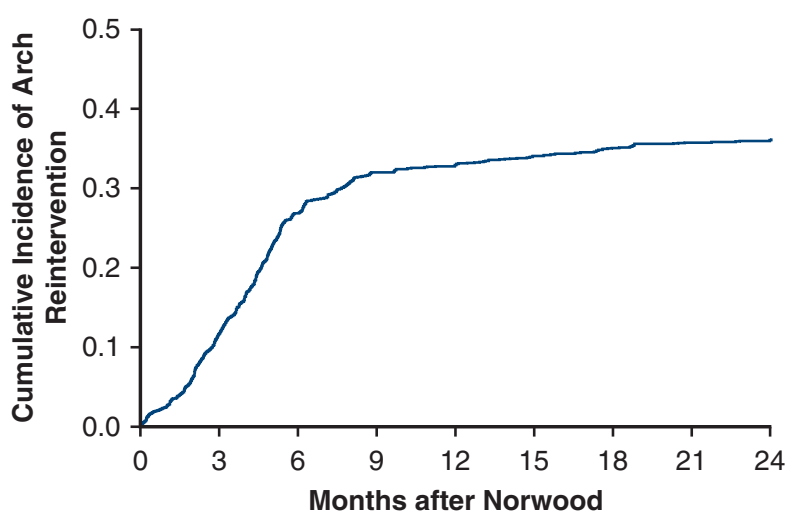

A
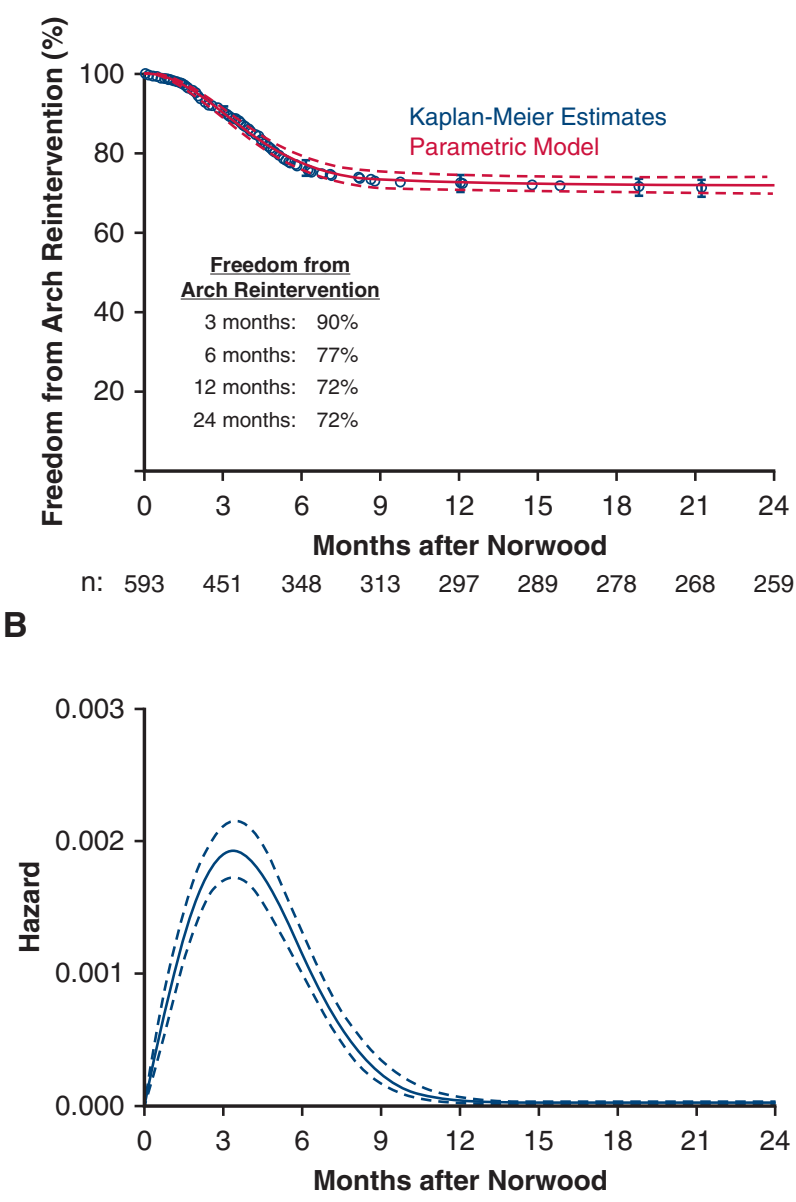

C

FIGURE 2. A, Cumulative incidence of arch reinterventions after the Norwood procedure. B, Unadjusted, time-related freedom from arch reinvention plot for the study population. Blue represent Kaplan-Meier estimates at events (arch reinterventions). Number at risk is indicated by $\mathrm{n}$ at time points along the horizontal axis. Solid red line represents parametric continuous point estimates with dashed lines containing the $70 \%$ confidence interval. $\mathrm{C}$, Hazard for first arch reintervention, which determines the continuous parametric point estimates in (A). It is represented by an early phase (131 events) and constant phase (15 events). Solid line represents the hazard with flanking dashed lines containing $70 \%$ confidence intervals. transplantation, and 20 underwent a biventricular conversion. After stage II procedures, there were 66 arch reinterventions, 54 transcatheter, and 12 surgical $(30 \%$ of all reinterventions; Figure 1).

\section{Repeated Arch Reinterventions}

A second arch reintervention after the Norwood procedure was performed in 49 patients $(33 \%$ of those with a first arch reintervention); 17 patients underwent a third reintervention, 5 underwent a fourth, and 1 patient underwent a fifth arch reintervention (Figure 1, inset). The cumulative incidence of arch reinterventions after the Norwood procedure is shown in Figure 2, A.

\section{Factors Associated With Arch Reintervention After the Norwood Procedure}

Arch reintervention after the Norwood procedure was represented by an early and constant phase hazard (Figure 2, $B$ and $C$ ). An interdigitating distal aortic anastomosis was performed in 79 neonates during their Norwood procedure, with 11 requiring arch reintervention $(14 \%)$. Among 515 infants not having interdigitation, 135 required arch reintervention $(26 \%)$. Of the patients who underwent interdigitation, $40(51 \%)$ were treated at 2 institutions, whereas the remaining $49 \%$ came from 11 institutions. Interdigitation tended to decrease prevalence of arch reintervention at both institutions where interdigitation was frequent and at centers where it was less commonly used. There was no significant trend in the prevalence of interdigitation use over time (Pearson correlation coefficient: $-0.25 ; P=.25$ ). In univariable analysis, the no-patch ascending neoaortic anastomosis, also referred to as the Brawn anastomosis, was associated with arch reintervention, with 5 of the 9 no-patch patients requiring arch reintervention $(56 \%$; Kaplan-Meier log rank $P=.006) .{ }^{18}$ Variables that were not significantly associated with arch reintervention included shunt type $(P=.5$; Figure E1), preoperative aortic sizes, and the composite variable for coarctectomy $(P=.12$; Table E2).

\section{Multivariable Modulated Renewal Model for Arch Reintervention After the Norwood Procedure}

In the multivariable model adjusted for institution and an interaction term between first arch reintervention and interdigitation (Table 2), interdigitation was protective against arch reintervention (Figures 3 and 4, and Video 1). Not undergoing arch reintervention before a stage II procedure was also protective of arch reintervention. Factors associated with increased risk of arch reintervention included the development of $\geq$ moderate right ventricle dysfunction, and development of $\geq$ moderate tricuspid valve regurgitation at any point (Figure 5). Previous catheter arch intervention increased the risk for arch reintervention, whereas previous surgical arch intervention was protective 
TABLE 2. Factors associated with arch reintervention after the Norwood procedure; modulated renewal analysis

\begin{tabular}{lccc}
\hline \multicolumn{1}{c}{ Variable } & $\begin{array}{c}\text { Parameter } \\
\text { estimate } \pm \text { STD }\end{array}$ & $\begin{array}{c}\boldsymbol{P} \\
\text { value }\end{array}$ & $\begin{array}{c}\text { Reliability, } \\
\%\end{array}$ \\
\hline $\begin{array}{l}\text { Previous stage II procedure } \\
\begin{array}{l}\text { Previous catheter arch } \\
\text { intervention }\end{array}\end{array}$ & $-0.96 \pm 0.20$ & $<.0001$ & 99 \\
$\begin{array}{l}\text { Previous surgical arch } \\
\text { intervention }\end{array}$ & $-0.37 \pm 0.19$ & .05 & 96 \\
$\begin{array}{l}\text { Interdigitation of the distal } \\
\text { aorta }\end{array}$ & $-0.68 \pm 0.33$ & .04 & 96 \\
\hline $\begin{array}{l}\text { Interdigitation of the distal } \\
\text { aorta interaction } \times \text { first } \\
\text { intervention }\end{array}$ & $1.16 \pm 0.53$ & .03 & 74 \\
\hline $\begin{array}{l}\text { Left atrial minor axis length, } \\
\text { cm }\end{array}$ & $-0.56 \pm 0.23$ & .02 & 71 \\
\hline $\begin{array}{l}\text { Development of } \geq \text { moderate } \\
\text { RV dysfunction }\end{array}$ & $0.63 \pm 0.23$ & .007 & 61 \\
\hline $\begin{array}{l}\text { Development of } \geq \text { moderate } \\
\text { tricuspid regurgitation }\end{array}$ & $0.32 \pm 0.19$ & .08 & 51 \\
\hline Institution J & $1.05 \pm 0.24$ & $<.0001$ & - \\
\hline $\begin{array}{l}\text { Institution I } \\
\text { Institution C }\end{array}$ & $0.89 \pm 0.25$ & .0003 & - \\
\hline \begin{tabular}{l} 
Institution M \\
\hline
\end{tabular} & $0.61 \pm 0.21$ & .004 & - \\
\hline
\end{tabular}

Multivariable parametric model (early phase) with institutional adjustment factors. Time $=0$ reset at each arch intervention. Previous stage II procedure, previous catheter/surgical arch intervention, development of $\geq$ moderate RV dysfunction, and development of $\geq$ moderate tricuspid regurgitation treated as time-varying covariables. STD, Standard deviation; $R V$, right ventricle.

(Figure 6). Patients with interdigitation who underwent arch reintervention were at increased risk of subsequent arch reintervention. Among all echocardiographic indices, only larger left atrial minor axis length was associated with reduced arch reintervention.

\section{Arch Reintervention and Mortality}

Mortality after the Norwood procedure was represented by an early and a constant phase hazard (Figure 7). Factors associated with mortality after the Norwood procedure are shown in Table 3. Arch reintervention time-varying covariables, including previous catheter arch procedure, previous surgical arch procedure, number of previous arch catheter procedures, number of previous arch surgical procedures, and number of all arch reinterventions, were not associated with mortality.

\section{Institutional Variability}

Arch reinterventions were performed at $19(83 \%)$ institutions. The median arch reintervention frequency (per 100 years patient follow-up) was 7.0 (Q1-Q3, 2.2-19.0; range, 0-40.0). There was no correlation between institutional reintervention incidence and institutional mortality

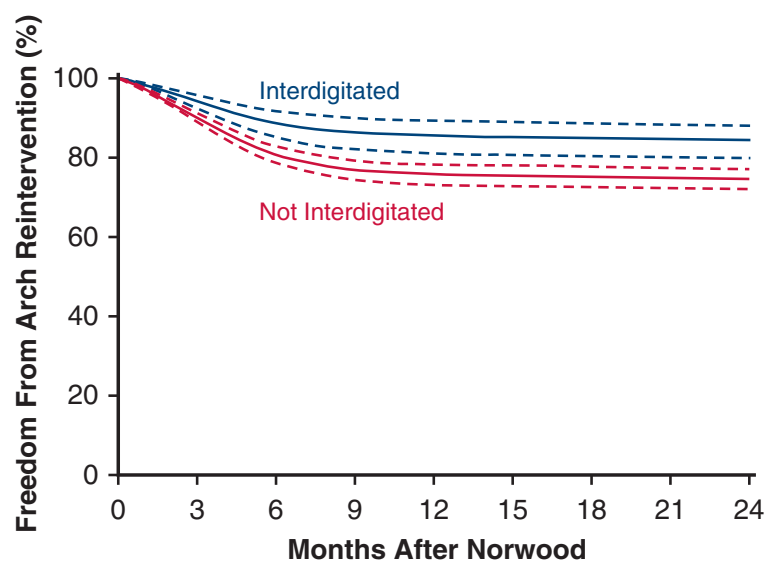

FIGURE 3. Parametric model solved for a single patient who has not yet progressed to stage II or undergone an arch reintervention after the Norwood procedure and has not developed $\geq$ moderate tricuspid regurgitation or right ventricle dysfunction, with left atrial minor axis length of $1.15 \mathrm{~cm}$ (median) stratified according to distal arch anastomosis technique. Dashed lines represent $70 \%$ confidence intervals.

rate at 1 year post-Norwood procedure (Pearson correlation coefficient: $-0.09 ; P=.72$ ). Preintervention gradients obtained via catheterization, available for 128 reinterventions, ranged from 0 to $64 \mathrm{~mm} \mathrm{Hg}$. The range of institutional median preintervention catheter gradients was 3 to $40 \mathrm{~mm} \mathrm{Hg}$. Among institutions for which $\geq 3$ preintervention catheter gradients were available ( $\mathrm{n}=11$ of 18$)$, there was no significant correlation between arch reintervention frequency and median preintervention gradient $(P=.3)$. Institutional practices did influence the likelihood of arch reintervention because 4 institutions, which contributed 26, 28, 58, and 17 patients respectively, were more likely to intervene on the arch.

\section{DISCUSSION \\ Principal Findings}

Arch reintervention occurred in $25 \%$ of our cohort. Interdigitation of the distal aortic anastomosis reduced the rate of arch reintervention, whereas postoperative tricuspid valve regurgitation and right ventricular dysfunction increased the likelihood of arch reintervention. Arch reintervention was not associated with increased mortality at 7 years. Repeated arch reintervention was less common after surgical rather than transcatheter arch reintervention. Finally, arch reintervention practices varied between institutions.

\section{Prevalence of Arch Reintervention After the Norwood Procedure}

We found that $25 \%$ of infants in our cohort underwent arch reintervention, which is within the range reported in previous publications, but higher than the $18 \%$ cumulative incidence of recoarctation found in the SVR trial. ${ }^{2-13}$ The Norwood subset of the CHSS Data Center Critical Left 


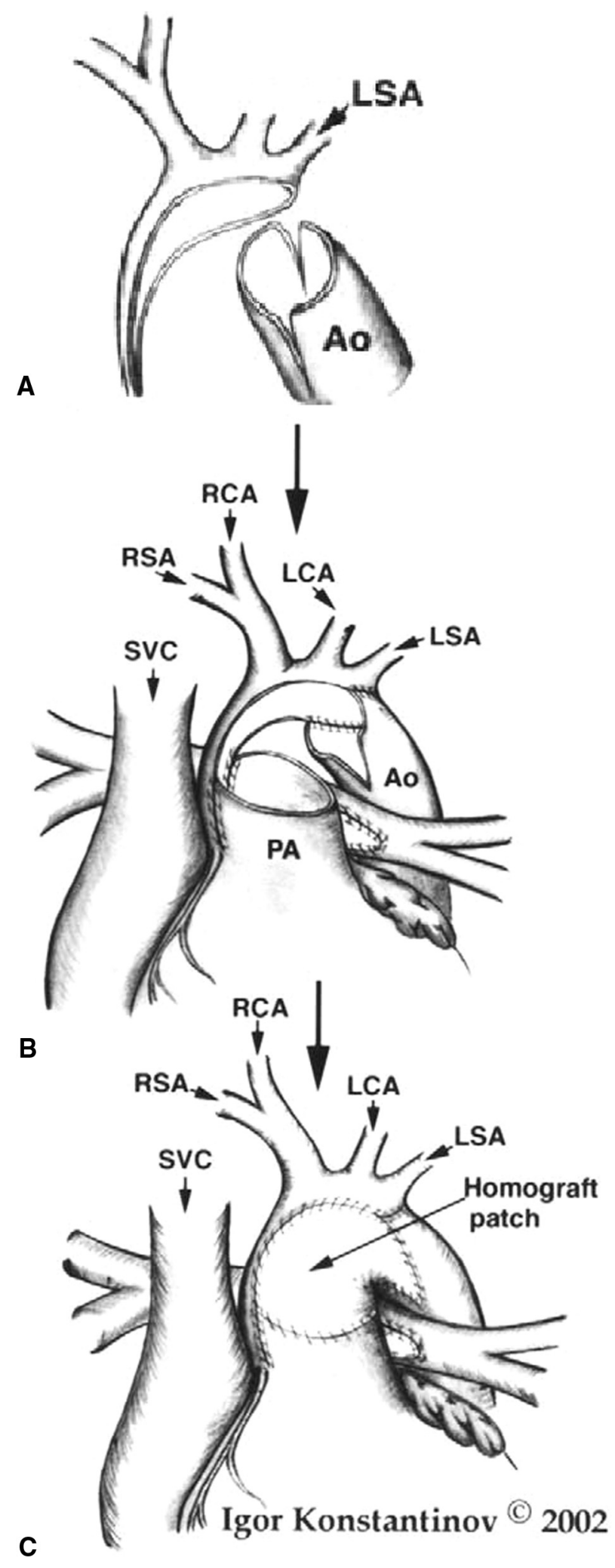

FIGURE 4. Surgical technique for interdigitating aortic arch anastomosis. All ductal tissue, including the periductal area, is removed. Two longitudinal incisions are made in the anterior and posterior walls of the descending aorta (A). An extended end to end anastomosis is constructed between the
Heart Obstruction cohort is unselected and contains patients from 23 institutions with varying size and the Norwood procedure experience. ${ }^{21}$ The $25 \%$ prevalence found in our study is within the range reported in previous publications. Our data show that repeat reinterventions on the reconstructed aortic arch are common, in agreement with previous studies. ${ }^{7,10-12,22}$

\section{Norwood Procedure Factors Associated With Arch Reintervention}

Interdigitation was associated with freedom from arch reintervention in our study. This benefit is likely because of the increased diameter and greater involvement of native tissue in the neoaorta-descending aorta anastomosis achieved via interdigitation. ${ }^{9}$ Establishing a wide, unobstructed anastomosis throughout the length of the neoaorta is a central tenet of the Norwood procedure. ${ }^{23}$ This must be balanced, however, with avoiding compression of the left pulmonary artery because complete resection of ductal tissue and coarctation has been associated with increased risk of subsequent left pulmonary artery intervention. ${ }^{24}$ Two retrospective, singleinstitution studies have reported on the surgical technique of interdigitation and its association with reduced arch reintervention. ${ }^{8,9}$ In our cohort, $51 \%$ of the interdigitated patients were treated at 1 of these 2 institutions. The protective effect of interdigitation only applied to freedom from the first aortic reintervention. When an interdigitated patient required an arch reintervention, they were at higher risk of a second reintervention compared with other distal anastomosis types. This suggests that when a patient requires an arch reintervention, the type of distal aortic anastomosis is no longer a factor in determining likelihood of future arch reinterventions. By reconstructing the outflow tract in patients with critical left heart obstruction, the neonate's risk for recoarctation is reset, evidenced by our finding that preoperative aortic sizes were not significantly associated with arch reintervention. The only baseline echocardiographic factor that was associated with arch reintervention was smaller left atrial minor axis length. This measurement did not significantly correlate with aortic sizes and had only moderate correlation with mitral valve and left ventricular size. Although we cannot explain the reason for this finding, it might be that patients with mitral stenosis and atresia might have other features unaccounted for in this study.

We further investigated whether the protective effect of interdigitation could be due to the accompanying complete

distal aortic arch and the posterior descending aorta (B). A homograft patch is then used to reconstruct the remainder of the $\operatorname{arch}(\mathrm{C})$. LSA, Left subclavian artery; $A o$, aorta; $R C A$, right common carotid artery; $R S A$, right subclavian artery; $L C A$, left common carotid artery; $S V C$, superior vena cava; $P A$, pulmonary artery. Reproduced with permission from Burkhart et al. ${ }^{8}$ 

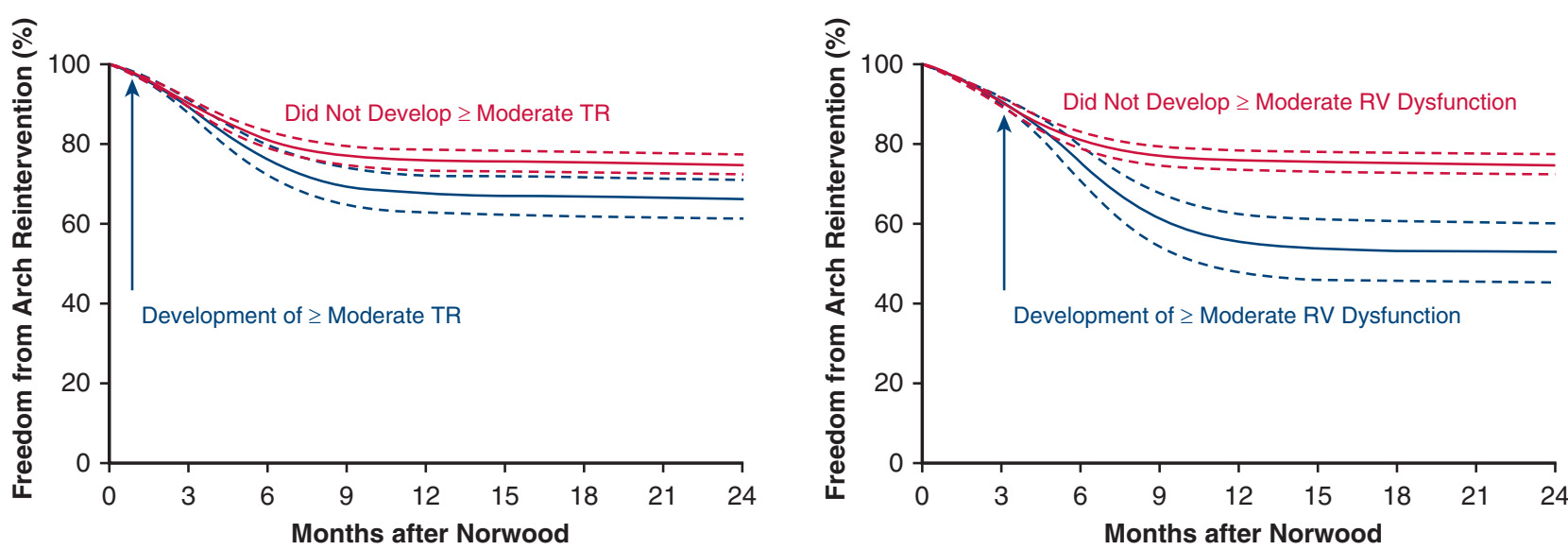

A

B

FIGURE 5. Parametric model solved for a single patient who does not have an interdigitated distal aortic anastomosis, has a left atrial minor axis length of $1.15 \mathrm{~cm}$ (median), has not undergone an arch reintervention after the Norwood procedure, has not yet progressed to stage II stratified according to: (A) the time-varying covariable of the development of $\geq$ moderate tricuspid valve regurgitation at 23 days (the median time to first $\geq$ moderate tricuspid valve regurgitation in the cohort, Q1-Q3: 6 to 154); (B) the time-varying covariable of the development of $\geq$ moderate right ventricle dysfunction at 98 days (the median time to first $\geq$ moderate right ventricle dysfunction). Dashed lines represent $70 \%$ confidence intervals. $T R$, Tricuspid valve regurgitation; $R V$, right ventricular.

ductal tissue removal by creating a composite variable labeled "complete coarctectomy." Any distal anastomosis that involved transection of the aorta with reanastomosis was considered a complete coarctectomy, with medial incision on the native aorta alone, which leaves the ductaladjacent posterior wall of the aorta in place, considered an incomplete coarctectomy. Consistent with previous studies, this complete coarctectomy variable was not associated with a statistically significant difference in arch

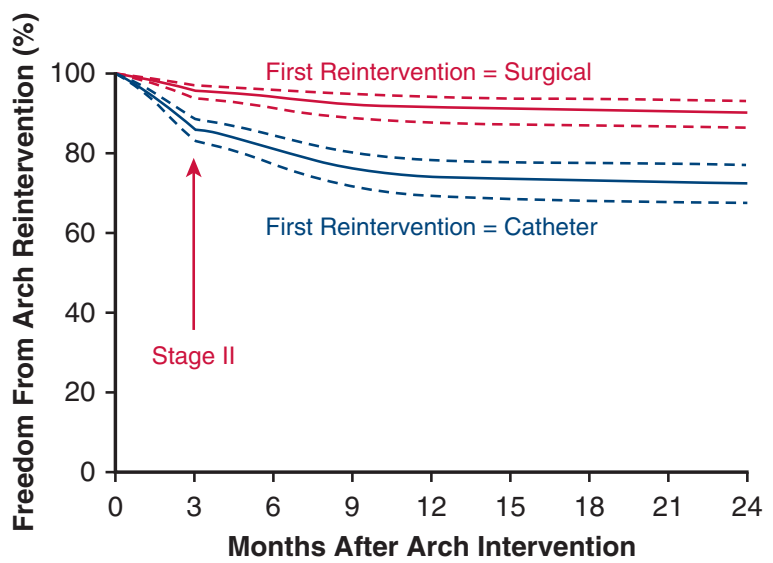

FIGURE 6. Modulated renewal parametric model solved for a single patient without an interdigitated distal aortic anastomosis, with left atrial minor axis length of $1.15 \mathrm{~cm}$ (median), no right ventricular dysfunction or tricuspid regurgitation, and who underwent a stage II procedure 3 months after arch reintervention stratified according to whether the first arch reintervention after the Norwood procedure was surgical or catheter. Time $=0$ is the time at which the first arch reintervention was performed. Dashed lines represent $70 \%$ confidence intervals. reintervention. ${ }^{2,10}$ Further, in our analysis of ascending neoaortic anastomosis types, the no-patch technique ${ }^{18}$ was associated with a high rate of arch reintervention.

In their analysis of the SVR trial data, Hill and colleagues reported that the presence of a right ventricle to pulmonary artery conduit was a risk factor for arch reintervention. ${ }^{10}$ The finding was on the basis of which shunt type was actually performed and was not associated with arch reintervention in the intention to treat analysis. ${ }^{10}$ In our nonrandomized, multi-institutional cohort, we did not find any statistically significant difference in arch reintervention rates on the basis of shunt type.

\section{Transcatheter and Surgical Arch Reintervention}

Transcatheter arch balloon aortoplasty is often the firstline therapy for arch obstruction after the Norwood procedure ${ }^{12}$ It is, however, associated with a high rate of reinterventions. ${ }^{7,10-12,22}$ The results from our modulated renewal analysis reinforce this finding, showing that previous transcatheter arch reintervention is associated with increased risk of subsequent arch reintervention. In contrast, we found that previous surgical reintervention was associated with reduced risk of subsequent arch reintervention. Surgical arch repair after the Norwood procedure has been shown to be safe and definitive with a low reintervention rate. ${ }^{7,12,25}$ The reduced reintervention rate with surgical aortoplasty must be balanced with the increased risk of surgery, including the possibility of recurrent laryngeal nerve injury. ${ }^{26}$ Our study was not designed to examine an inflection point or patient population in which surgical therapy might be indicated in lieu of balloon aortoplasty, but it might be reasonable to consider 

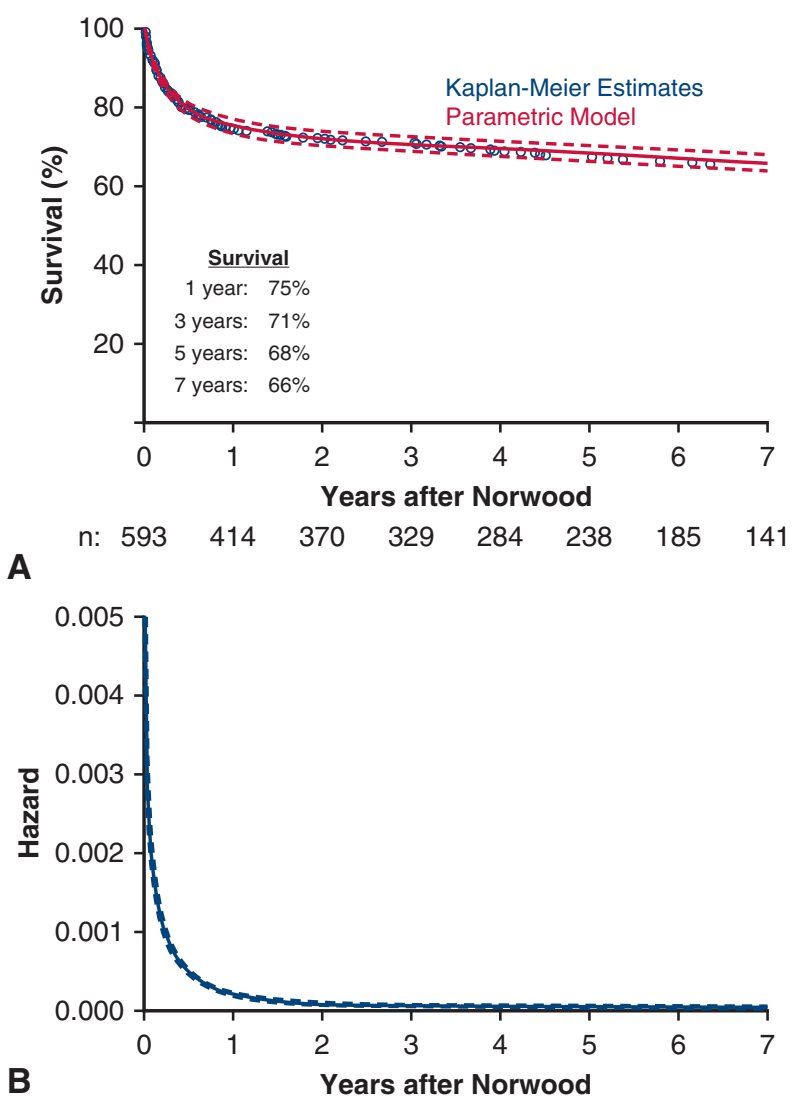

FIGURE 7. Mortality after the Norwood procedure; (A) unadjusted, timerelated survival for the study population. Red circles represent actuarial Kaplan-Meier estimates at events (deaths). Number at risk is indicated by $\mathrm{n}$ at time points along the horizontal axis. Solid black line represents parametric continuous point estimates with dashed lines containing the $70 \%$ confidence interval. B, Hazard for mortality, which determines the continuous parametric point estimates in (A). It is represented by an early phase (152 events) and constant phase (38 events). Dashed lines represent $70 \%$ confidence intervals.

surgical aortoplasty in those with persistent gradients after initial transcatheter reintervention. Our data show that patients who do not require an arch reintervention before stage II palliation are less likely to require arch reintervention later. However, in those who have undergone a balloon dilation in the first interstage period, consideration should be given to surgical repair of the aortic arch during a stage II procedure or biventricular conversion. Performing arch repair increases the complexity of the stage II procedure, but might be an opportunity to prevent further arch procedures and the possible sequelae of arch obstruction.

\section{Tricuspid Valve Regurgitation and Ventricular Dysfunction}

The increased afterload on the single right ventricle created by arch obstruction can lead to ventricular dysfunction and tricuspid valve regurgitation. ${ }^{14,27}$ Additional
TABLE 3. Factors associated with mortality after Norwood procedure

\begin{tabular}{|c|c|c|c|}
\hline Variable & $\begin{array}{c}\text { Parameter } \\
\text { Estimate } \pm \text { STD }\end{array}$ & $\begin{array}{c}P \\
\text { value }\end{array}$ & $\begin{array}{c}\text { Reliability, } \\
\%\end{array}$ \\
\hline \multicolumn{4}{|l|}{ Early phase } \\
\hline Birth weight, $\mathrm{kg}$ & $-0.90 \pm 0.21$ & $<.0001$ & 87 \\
\hline Presence of Sano shunt & $-0.78 \pm 0.20$ & .0001 & 75 \\
\hline Aortic valve atresia & $0.76 \pm 0.23$ & .001 & 74 \\
\hline $\begin{array}{l}\text { Cardiopulmonary bypass } \\
\text { time, minutes }\end{array}$ & $0.006 \pm 0.002$ & .001 & 69 \\
\hline Tricuspid valve procedure & $1.59 \pm 0.63$ & .01 & 54 \\
\hline Institution L & $1.00 \pm 0.38$ & .01 & - \\
\hline \multicolumn{4}{|l|}{ Constant phase } \\
\hline $\begin{array}{l}\text { Development of } \geq \\
\text { moderate tricuspid valve } \\
\text { regurgitation }\end{array}$ & $1.10 \pm 0.34$ & .001 & 77 \\
\hline $\begin{array}{l}\text { Development of } \geq \\
\text { moderate RV } \\
\text { dysfunction }\end{array}$ & $1.49 \pm 0.39$ & .0001 & 71 \\
\hline Previous stage II procedure & $-1.40 \pm 0.35$ & $<.0001$ & 66 \\
\hline
\end{tabular}

Multivariable parametric model (early and constant phase hazard) with institutional adjustment factors for mortality after the Norwood procedure (time $=0$ ). It is notable that the time-varying covariables pertaining to arch intervention were not significant in the model. $S T D$, Standard deviation; $R V$, right ventricle.

research has identified right ventricular strain and tricuspid valve regurgitation as predictors of the presence of arch obstruction. ${ }^{28,29}$ By incorporating the degree of postoperative ventricular dysfunction and tricuspid valve regurgitation as time-varying covariables in our analysis, we were able to show that $\geq$ moderate ventricular dysfunction and $\geq$ moderate tricuspid valve regurgitation are associated with arch reintervention. These associations were present in the multivariable model, which also included the stage II procedure. The stage II procedure reduces volume load on the systemic right ventricle and has been shown to promote remodeling of the systemic right ventricle, but the relationship with tricuspid regurgitation is less well established. ${ }^{30-32}$

Echocardiographic evaluation of the gradient across the aortic arch is inaccurate, particularly in the setting of right ventricular dysfunction and tricuspid valve regurgitation in the post-Norwood population. ${ }^{28,33,34}$ However, our data would suggest that these echocardiographic findings are important because they might indicate the need for arch reintervention, or at least transcatheter evaluation of the aortic arch, even in the absence of a significant echocardiographic arch gradient.

\section{Association of Arch Reintervention and Mortality}

Arch obstruction is a cause of death after the Norwood procedure. ${ }^{1}$ However, it is less clear whether a patient who undergoes a reintervention for arch coarctation is at increased risk for death. Previous studies have analyzed this question using conditional survival analyses selecting for patients who survived a set duration of time after the Norwood procedure or selecting for patients who underwent pre- 


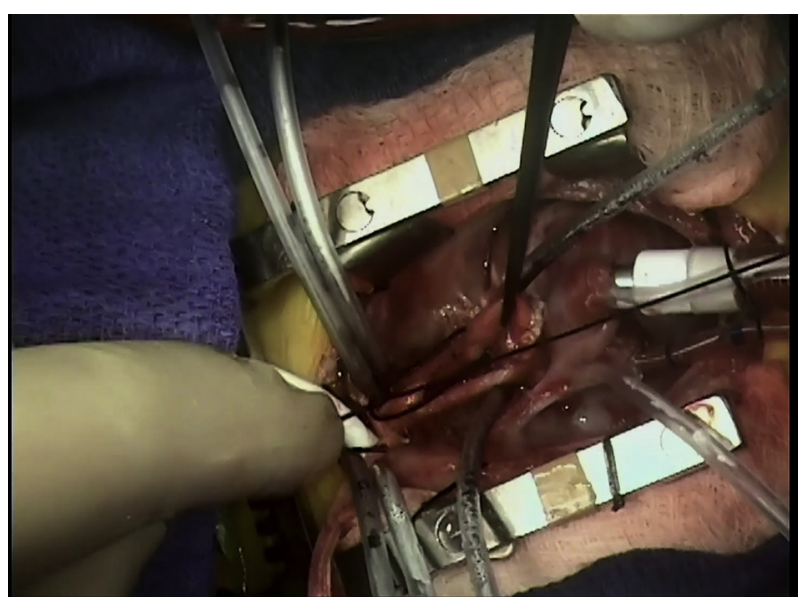

VIDEO 1. Surgical technique of arch reconstruction during the Norwood procedure showing interdigitation of the distal aortic anastomosis. Performed by James S. Tweddell, MD. Courtesy of James S. Tweddell, MD. Video available at: https://www.jtcvs.org/article/S0022-5223(18)33114-3/ fulltext.

stage II cardiac catheterization. ${ }^{7,10,14}$ These studies have shown no difference in mortality. Our study also showed that arch reintervention is not associated with increased mortality. Understanding these relationships is complex, because important coarctation has potential physiologic consequences, such as propensity for worse systemic ventricular function and systemic atrioventricular valvar regurgitation. These might lead to decreased long-term survival or worse Fontan candidacy. Our data suggest that participating centers are closely monitoring their patients and intervening on arch obstruction before it affects survival at 7 years. The risk factors for death after the Norwood procedure in this cohort have been recently reported in a separate CHSS study and are not the focus of this report. ${ }^{35}$

\section{Institutional Variability}

The lack of a standardized definition of what constitutes significant arch obstruction after the Norwood procedure has led to wide variation in institutional reintervention frequency and preintervention gradient. Our data show that institutional practices influence likelihood of arch reintervention. In our cohort there was no statistically significant correlation between preintervention gradient and institution arch reintervention incidence, a finding also reported in the SVR trial data. ${ }^{10}$ This is likely attributable to the threshold for reintervention varying from patient to patient and presents the opportunity for development of reintervention guidelines. Although our study is unable to provide definition criteria, it does provide evidence that a standardized definition should not be on the basis of gradient alone. A standardized definition should incorporate factors such as right ventricular dysfunction and tricuspid valve regurgitation.

\section{Limitation}

The primary limitation of our study is inability to analyze arch obstruction. In lieu of studying arch obstruction, we analyzed arch intervention. Although arch intervention and obstruction are related, arch intervention is not a perfect surrogate for obstruction because it requires recognition of arch obstruction and the decision to intervene. The threshold for intervention varies across institutions and patient situations. Therefore, these findings provide the opportunity for inference, but not direct application to arch obstruction. Factors that prevented the study of arch obstruction included: inadequacy of charting of arch gradient over time, a consequence of the nonprotocolized ascertainment of metrics; unknown arch patency for the deceased patients, creating the possibility of informative censoring; and the lack of a standardized definition by which to classify a patient's arch as obstructed. The inadequacy of gradient charting also prevented determination of postintervention gradients. Further, as a multi-institutional prospective cohort study, our data are subject to possible selection bias because of incomplete enrollment of all of a participating institution's eligible patients (Appendix E1). Finally, the low frequency of transcatheter aortic stenting might have affected the durability of the transcatheter interventions in our study, although because of the low number we were unable to analyze this thoroughly.

\section{CONCLUSIONS}

Although prevalent, aortic reinterventions after the Norwood procedure are not associated with increased mortality. Serial surveillance for arch obstruction after the Norwood procedure, including integrating changes in systemic right ventricle function and tricuspid valve insufficiency, is important to optimize outcomes. If transcatheter therapy has failed in a post-Norwood patient, surgical correction of aortic obstruction may be considered to prevent further reintervention. A standardized definition of arch obstruction is needed to reduce the wide variation in arch reintervention practices and enable further study of its role in post-Norwood procedure mortality.

\section{Webcast}

You can watch a Webcast of this AATS meeting presentation by going to: https://aats.blob.core.windows.net/ media/18Apr29/30ABC\%20Congenital\%20SS/S52_1_ webcast_031740422.mp4.

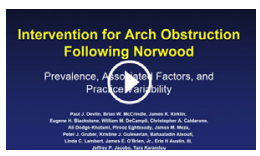




\section{Conflict of Interest Statement}

Authors have nothing to disclose with regard to commercial support.

The authors thank Sally Cai, Brenda Chow, Kristina Kovach, Arti Singh, Julia Lo, and Kate Pearson from the CHSS Data Center staff. The authors acknowledge the invaluable contributions of the data coordinators at CHSS institutions, especially Linda Lambert, Trupti Shah, Violet Carey, Diana Connelly, and Joseph Moryousef-Abitol, who participated in remote data extraction. Finally, the CHSS recognizes the major contribution from the patients and their families in all of the CHSS cohorts, without whom such studies would not be possible.

\section{References}

1. Bartram U, Grunenfelder J, Van Praagh R. Causes of death after the modified Norwood procedure: a study of 122 postmortem cases. Ann Thorac Surg. 1997:64:1795-802.

2. Ashcraft TM, Jones K, Border WL, Eghtesady P, Pearl JM, Khoury PR, et al. Factors affecting long-term risk of aortic arch recoarctation after the Norwood procedure. Ann Thorac Surg. 2008;85:1397-402.

3. Bautista-Hernandez V, Marx GR, Gauvreau K, Pigula FA, Bacha EA, Mayer JE Jr, et al. Coarctectomy reduces neoaortic arch obstruction in hypoplastic left heart syndrome. J Thorac Cardiovasc Surg. 2007;133:1540-6.

4. Chessa M, Dindar A, Vettukattil JJ, Stumper O, Wright JG, Silove ED, et al. Balloon angioplasty in infants with aortic obstruction after the modified stage I Norwood procedure. Am Heart J. 2000;140:227-31.

5. Tworetzky W, McElhinney DB, Burch GH, Teitel DF, Moore P. Balloon arterioplasty of recurrent coarctation after the modified Norwood procedure in infants. Catheter Cardiovasc Interv. 2000;50:54-8.

6. Zellers TM. Balloon angioplasty for recurrent coarctation of the aorta in patients following staged palliation for hypoplastic left heart syndrome. Am J Cardiol. 1999;84:231-3.

7. Zeltser I, Menteer J, Gaynor JW, Spray TL, Clark BJ, Kreutzer J, et al. Impact of re-coarctation following the Norwood operation on survival in the balloon angioplasty era. J Am Coll Cardiol. 2005;45:1844-8.

8. Burkhart HM, Ashburn DA, Konstantinov IE, De Oliveira NC, Benson L, Williams WG, et al. Interdigitating arch reconstruction eliminates recurrent coarctation after the Norwood procedure. J Thorac Cardiovasc Surg. 2005;130:61-5.

9. Lamers LJ, Frommelt PC, Mussatto KA, Jaquiss RD, Mitchell ME, Tweddell JS. Coarctectomy combined with an interdigitating arch reconstruction results in a lower incidence of recurrent arch obstruction after the Norwood procedure than coarctectomy alone. J Thorac Cardiovasc Surg. 2012;143:1098-102.

10. Hill KD, Rhodes JF, Aiyagari R, Baker GH, Bergersen L, Chai PJ, et al. Intervention for recoarctation in the single ventricle reconstruction trial: incidence, risk, and outcomes. Circulation. 2013;128:954-61.

11. Sakurai T, Rogers V, Stickley J, Khan N, Jones TJ, Barron DJ, et al. Single-center experience of arch reconstruction in the setting of Norwood operation. Ann Thorac Surg. 2012;94:1534-9.

12. Porras D, Brown DW, Marshall AC, Del Nido P, Bacha EA, McElhinney DB. Factors associated with subsequent arch reintervention after initial balloon aortoplasty in patients with Norwood procedure and arch obstruction. J Am Coll Cardiol. 2011;58:868-76.

13. Whiteside W, Hancock HS, Pasquali SK, Yu S, Armstrong AK, Menchaca A, et al. Recurrent coarctation after neonatal univentricular and biventricular Norwood-type arch reconstruction. Ann Thorac Surg. 2016;102:2087-94.

14. Ballweg JA, Dominguez TE, Tabbutt S, Rome JJ, Gaynor JW, Nicolson SC, et al. Reintervention for arch obstruction after stage 1 reconstruction does not adversely affect survival or outcome at Fontan completion. J Thorac Cardiovasc Surg. 2010;140:545-9.

15. Meza JM, Slieker M, Blackstone EH, Mertens L, DeCampli WM, Kirklin JK, et al. A novel, data-driven conceptualization for critical left heart obstruction. Comput Methods Programs Biomed. 2018;165:107-16.

16. Blackstone EH, Naftel DC, Turner ME. The decomposition of time-varying hazard into phases, each incorporating a separate stream of concomitant information. J Am Stat Assoc. 1986;81:615-24.

17. Cook RJ, Lawless JF. Analysis of repeated events. Stat Methods Med Res. 2002; 11:141-66
18. Ishino K, Stumper O, De Giovanni JJ, Silove ED, Wright JG, Sethia B, et al. The modified Norwood procedure for hypoplastic left heart syndrome: early to intermediate results of 120 patients with particular reference to aortic arch repair. $J$ Thorac Cardiovasc Surg. 1999;117:920-30.

19. Breiman L. Bagging predictors. Mach Learn. 1996;24:123-40.

20. Ku HH. Notes on the use of propagation of error formulas. J Res Natl Bur Stand. 1966;70C:263.

21. Hickey EJ, McCrindle BW, Caldarone CA, Williams WG, Blackstone EH. Making sense of congenital cardiac disease with a research database: the Congenital Heart Surgeons' Society data center. Cardiol Young. 2008;18:152-62.

22. Soongswang J, McCrindle BW, Jones TK, Vincent RN, Shu DT, Kuhn MA, et al. Outcomes of transcatheter balloon angioplasty of obstruction in the neo-aortic arch after the Norwood operation. Cardiol Young. 2001;11:54-61.

23. Tweddell JS. The Norwood procedure with an innominate artery-to-pulmonary artery shunt. Oper Tech Thorac Cardiovasc Surg. 2005;10:123-40.

24. Griselli M, McGuirk SP, Ofoe V, Stumper O, Wright JG, de Giovanni JV, et al Fate of pulmonary arteries following Norwood procedure. Eur J Cardiothorac Surg. 2006;30:930-5.

25. Mery CM, Khan MS, Guzman-Pruneda FA, Verm R, Umakanthan R, Watrin CH, et al. Contemporary results of surgical repair of recurrent aortic arch obstruction. Ann Thorac Surg. 2014;98:133-41.

26. Davies RR, Carver SW, Schmidt R, Keskeny H, Hoch J, Pizarro C. Laryngopharyngeal dysfunction independent of vocal fold palsy in infants after aortic arch interventions. J Thorac Cardiovasc Surg. 2014;148:617-24.e2.

27. Larrazabal LA, Selamet Tierney ES, Brown DW, Gauvreau K, Vida VL, Bergersen L, et al. Ventricular function deteriorates with recurrent coarctation in hypoplastic left heart syndrome. Ann Thorac Surg. 2008;86:869-74.

28. Fraisse A, Colan SD, Jonas RA, Gauvreau K, Geva T. Accuracy of echocardiography for detection of aortic arch obstruction after stage I Norwood procedure. Am Heart J. 1998;135:230-6.

29. Raucci FJ Jr, Seckeler MD, Saunders C, Gangemi JJ, Peeler BB, Jayakumar KA Right-ventricular global longitudinal strain may predict neo-aortic arch obstruction after Norwood/Sano procedure in children with hypoplastic left heart syndrome. Pediatr Cardiol. 2013;34:1767-71.

30. Yamagishi S, Masuoka A, Uno Y, Katogi T, Suzuki T. Influence of bidirectional cavopulmonary anastomosis and concomitant valve repair on atrioventricular valve annulus and function. Ann Thorac Surg. 2014;98:641-7.

31. Kasnar-Samprec J, Kuhn A, Horer J, Vogt M, Cleuziou J, Lange R, et al. Unloading of right ventricle by bidirectional superior cavopulmonary anastomosis in hypoplastic left heart syndrome patients promotes remodeling of systemic right ventricle but does not improve tricuspid regurgitation. J Thorac Cardiovasc Surg. 2012; 144:1102-9.

32. Mahle WT, Cohen MS, Spray TL, Rychik J. Atrioventricular valve regurgitation in patients with single ventricle: impact of the bidirectional cavopulmonary anastomosis. Ann Thorac Surg. 2001;72:831-5.

33. Wisotzkey BL, Hornik CP, Green AS, Barker PC. Comparison of invasive and non-invasive pressure gradients in aortic arch obstruction. Cardiol Young. 2015;25:1348-57.

34. Fundora MP, Sasaki J, Muniz JC, Rossi A, Rhodes JF Jr, Hannan RL, et al. Evaluation of residual coarctation in infants with a single right ventricle after stage I palliation. Pediatr Cardiol. 2017;38:115-22.

35. Meza JM, Hickey E, McCrindle B, Blackstone E, Anderson B, Overman D, et al. The optimal timing of stage-2-palliation after the Norwood operation. Ann Thorac Surg. 2018;105:193-9.

36. Jacobs JP, Pasquali SK, Austin E, Gaynor JW, Backer C, Hirsch-Romano JC et al. Linking the congenital heart surgery databases of the Society of Thoracic Surgeons and the Congenital Heart Surgeons' Society: part 1-rationale and methodology. World J Pediatr Congenit Heart Surg. 2014;5:256-71.

37. Jacobs JP, Pasquali SK, Austin E, Gaynor JW, Backer C, Hirsch-Romano JC et al. Linking the congenital heart surgery databases of the Society of Thoracic Surgeons and the Congenital Heart Surgeons' Society: part 2-lessons learned and implications. World J Pediatr Congenit Heart Surg. 2014;5:272-82.

38. Nelson W. Theory and applications of hazard plotting for censored failure data. Technometrics. 1972;14:945-66.

39. Yuan Y. Multiple Imputation for Missing Data: Concepts and New Developments. Rockville, Md: SAS Institute Inc; 2002.

Key Words: Norwood, neoaorta, arch obstruction, coarctation, interdigitation, hypoplastic left heart syndrome, critical left heart obstruction 


\section{Discussion}

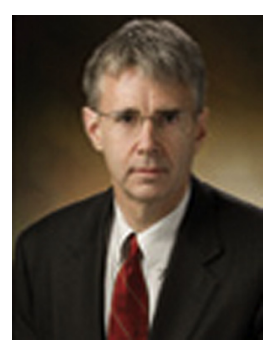

Dr J. William Gaynor (Philadelphia,

$P a)$. I want to thank the authors for a very nice study and for allowing me to review the manuscript. This is an excellent study with a very complicated and involved analysis, and again, they are to be congratulated. They have utilized a large inception cohort of newborns with hypoplastic left heart syndrome who were part of a larger cohort of those with critical left heart obstruction enrolled by the CHSS, and in this analysis they evaluated the prevalence and consequences of reintervention for arch obstruction after the Norwood procedure.

Arch reintervention was performed in approximately $25 \%$ to $30 \%$ of the cohort. The reintervention was usually performed before the stage II operation. Catheter reintervention was the most common technique utilized but was associated with a greater need for a second or third reintervention. They identified no effects of need for reintervention on survival.

Importantly, they also showed that it is possible that a technical modification of how the distal arch reconstruction is performed, that is, use of an interdigitating reconstruction, was protective against reintervention, at least for a first intervention.

There are a couple of questions that I have for the authors, and these are based mainly on difficulties in interpreting data from this type of study. First of all, this is a study of patients enrolled over approximately 11 years from over 20 institutions, and with even 600 patients, that's an average of about 2 to 3 patients per year per institution. Most institutions perform more than 2 Norwoods a year. So how do we know that there is not some sort of enrollment bias, that there were many patients undergoing a Norwood at these institutions who were not enrolled in the study? We do not have data on the number of total eligible patients, those who failed to consent, et cetera. How can we be sure that these data are generalizable to the larger population? This is not a criticism of the study. It's a difficulty with these multiinstitutional studies in general.

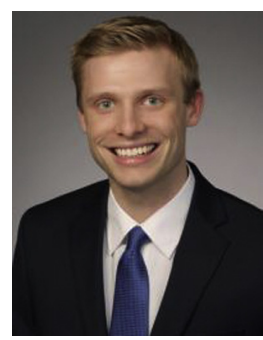

Dr Paul Joseph Devlin (Toronto, Ontario, Canada). Yes. The CHSS has over 80 member institutions, and 23 of those institutions contributed Norwood patients to this cohort. We rely on the voluntary submission of patient records to the CHSS data center. The enrollment is not incentivized and therefore might take a lower priority in the busy data coordinator's schedule.

While I agree that we are not capturing everyone, I think it's important to attempt to define the denominator. Previous attempts have involved creating a linkage with the STS congenital heart database. That's a surgical cohort as opposed to our diagnosis inception cohorts, and currently progress is ongoing with that linkage.

I think that the best we can do is hope that the voluntary submission of patients is random selection, but there is certainly a potential for selection bias.

Dr Gaynor. Is there anything you would suggest in future study design, such as maintaining a list of eligible patients at each institution or requiring that as participation? That doesn't mean they need to be approached, but at least you could get the true denominator.

Dr Devlin. Yes, I think that's a great idea.

Dr Gaynor. Finally, in the manuscript and not discussed here, one of the difficulties is that you are basing the analysis on performance of an intervention, and there are no consistent data on the indications for that intervention, and as you show in the manuscript, the indications varied tremendously across institutions. Some institutions performed almost no reinterventions, others performed many reinterventions; in some the gradient measures were $<5 \mathrm{~mm} \mathrm{Hg}$ and they had an intervention.

So, first of all, how can you assess the true rate of significant obstruction when there is no defined criteria for reintervention and the criteria seemed to vary tremendously across the institutions? Also, how can you be sure that the rates are the same and not just a threshold that we did a cath, the kid was a little blue or had a little bit of TR, so it looked okay but we ballooned it anyway? How can we do this, because this is very important in terms of interpreting whether or not the differences in technique actually did translate to a lower rate of reintervention.

Dr Devlin. Absolutely. Initially we wanted to study arch obstruction. We were limited in that we had a nonprotocolized collection of metrics, such as arch gradient, whether by echo or catheter. When we went to analyze arch gradient after Norwood, we found a high proportion of missing values for aortic arch gradient. That left us pretty limited, so we used intervention instead as a surrogate for obstruction, which has the problems that you have alluded to where there is a lot of variability within institutional intervention thresholds. It's clear from our data that RV dysfunction and tricuspid regurgitation are playing a role in whether an institution decides to intervene.

We tried to accommodate some of the variation by including institution as variables and adjustment factors in our analysis.

Dr Gaynor. I think this is important, because, as you outline in the manuscript, 78 patients had the interdigitated technique and most of those were performed at only 2 institutions and only approximately half of the institutions used the technique at all. So there could be a relationship between those institutions and the performance of that strategy and that institution's threshold for reintervention. 
As an example, an institution that is more likely to do transcatheter balloon interventions might have a lower threshold than one that is going to do a surgicalrelated intervention. How can we interpret your findings with that type of interinstitutional variation?

Dr Devlin. As you mentioned, there were 78 interdigitated patients in our cohort and 40 of them came from 2 institutions who were known to use interdigitation. The remaining 38 patients came from 11 different institutions. We saw a reduction in arch reintervention with interdigitation in both of those groups. However, there is certainly a wide discrepancy between institutions with regard to how frequently they are using interdigitation.

In our analysis, we created variables for the institutions and placed them into the model one by one to ensure that interdigitation was not a marker for what institution a patient was coming from but rather that it was the interdigitation that was affecting the effect.

Dr Gaynor. And it looked like in your multivariable model that the effect of institution was a little bit stronger than the effect of surgical technique on the use of reintervention. Is that correct?

Dr Devlin. We did have institutions that entered into the model. Those were not the interdigitating institutions, likely because the interdigitation was accounting for those institutions, but there were institutions in our cohort that rarely intervened on the arch and therefore that was a strong predictor.

Dr Gaynor. Thank you very much. And again, congratulations on an outstanding study.

Dr Devlin. Thank you.

Unidentified Speaker. Nice presentation. I just had 1 question. Maybe either you or Dr Blackstone can explain the statistics to me. So not to belabor this, you said the interdigitating technique resulted in fewer first arch reinterventions, but then you also said that coarctectomy was not a risk factor for increased arch obstruction. So how do these 2 things reconcile?

Dr Devlin. We looked at this in 2 different ways. First we looked at all the different types of distal aortic anastomoses, and interdigitation was statistically associated with reduced arch intervention. Then we created a composite variable for coarctectomy, which included interdigitated patients as well as other patients who could be considered to have a complete coarctectomy; those whose descending aortas were completely transsected, the superior wall of the aorta was transsected and removed across from the ductus. In that group of patients coarctectomy did not reduce the frequency of arch reintervention. So it was the interdigitated patients and not simply the coarctectomy group that was affected in reducing arch reintervention.

Unidentified Speaker. But most contemporary surgeons who do a coarctectomy do a counterincision posteriorly, anteriorly in advanced aorta. So, anyway, for perspective.

Dr Devlin. In our cohort it was 78 patients who were interdigitated and approximately 90 who had transsection of the aorta with a medial incision alone or a transection of the aorta with an endtoend anastomosis without a mention of a counterincision on that posterolateral aspect.

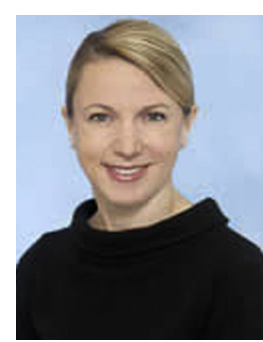

Dr Jennifer Hirsch-Romano (Ann Arbor, Mich). There are several studies that have shown that shunt type is associated with arch obstruction later on When you looked at shunt type was there a difference between centers and use of different shunt types that might have played into the equation?

Dr Devlin. We didn't look specifically at the difference in shunt type usage by institution, but within our cohort it was almost split right down the middle between BT shunts and Sano shunts, and we saw no significant effect on arch reintervention between those 2 groups.

Dr Hirsch-Romano. Was the use of the shunt types similar across the institutions, because there tends to be center preferences?

Dr Devlin. Within the critical left heart obstruction cohort, there are institutional preferences for shunt type usage with certain centers performing Norwoods with mostly BT shunts or Sano shunts.

Dr Hirsch-Romano. And I presume this excluded any patient with a previous hybrid stage I palliation?

Dr Devlin. We included patients with previous hybrid stage I palliations. These patients ultimately underwent a Norwood procedure and were thus included in the study cohort.

Dr Hirsch-Romano. How many patients were there?

Dr Devlin. There were 30 hybrid patients. 


\section{APPENDIX E1. CHSS PATIENT ENROLLMENT}

As a voluntary database, the CHSS Data Center does not capture all of the eligible patients at participating institutions. The CHSS Data Center has partnered with the Society of Thoracic Surgeons (STS) to link the CHSS enrollment numbers with the STS Congenital Heart Surgery Database surgical data. ${ }^{36,37}$ Using the data in the STS Congenital Heart Surgery Database, patient eligibility for CHSS cohorts were assessed, establishing a denominator of eligible patients. For the Norwood procedure, 227 patients of 1995 eligible patients $(11 \%)$ at all potential centers were enrolled in the CHSS Critical Left Heart Obstruction Cohort (formerly known as LVOTO). This proportion was higher among actively enrolling centers (34\%). In a comparison of the enrolled versus nonenrolled patients, in-hospital mortality ( $15 \%$ vs $16 \%$, respectively) and median postoperative length of stay (31 days vs 26 days, respectively) were similar. The groups were also similar with regard to age, sex, and other demographic factors.

\section{MULTIPHASE PARAMETRIC MODELING AND MODULATED RENEWAL}

To perform the multiphase parametric modeling, ${ }^{16}$ we first analyzed freedom from arch reintervention, censoring at death, and end of follow-up, with arch reintervention as the end point. Variables identified in this model were scrutinized in the modulated renewal model with interaction terms with first arch reintervention. To create the modulated renewal model, ${ }^{17}$ the cumulative incidence of reintervention was estimated nonparametrically using the Nelson method. ${ }^{38}$ Visual inspection of the risk of each subsequent reintervention revealed similar temporal patterns (Figure E2). Patients who experienced a first arch reintervention after the Norwood procedure were restarted at a new time 0 and tracked to the next event, and so forth, for each successive reintervention. The cumulative hazard for all reinterventions $(\mathrm{n}=218)$ for the 146 patients was then modeled.

\section{IMPUTATION}

Multiple imputation was performed using PROC MI for missing values, which yielded 5 data sets with imputed missing values from which parameter estimates were obtained. The Markov Chain Monte Carlo method was used for the arbitrary missing pattern to create imputations by using simulations from a Bayesian prediction distribution. ${ }^{39}$ These parameter estimates were then combined to obtain a final parameter estimate and confidence interval. Categorical variables were imputed via linear discriminant analysis with a CLASS and FCS statement. A missing value indicator variable was created and tested as a covariate in the regression analysis to verify that the presence of missing data for that factor was not itself associated with the event being analyzed.

\section{BOOTSTRAPPING AND FINAL MULTIVARIABLE MODEL}

Bootstrap aggregation was used to aid variable selection (500 resamples). ${ }^{19}$ The data set was sampled with replacement to generate 500 different data sets each with 593 patients. The multivariable analysis was performed on each of these data sets, generating 500 bootstrapped models. Individual and closely clustered variables (eg, various transformations of scale of the same variable, or dummy variables for the same risk factor) that appeared in $>50 \%$ of the bootstrapped models and variables indicating each patient's institution were included in the final multivariable risk hazard analysis. The final multivariable risk hazard analysis used forward stepwise variable selection with $P<.10$ for entry and $P<.05$ for retention. 


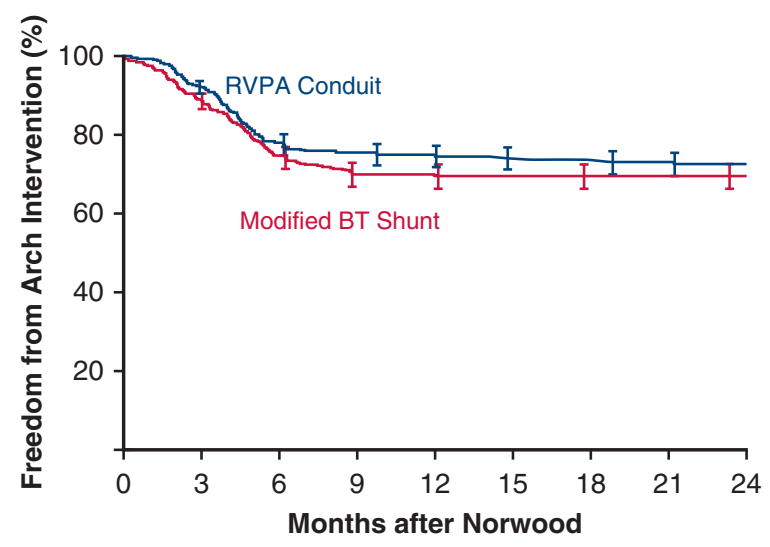

Number at Risk:

RVPA: $242188 \quad 171 \quad 162 \quad 157 \quad 149 \quad 142 \quad 138$

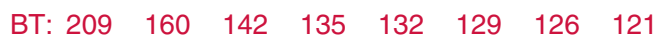

FIGURE E1. Kaplan-Meier depiction of freedom from arch intervention after the Norwood procedure stratified on the basis of shunt type. Log rank $P=.5$. Seventy-four of $296(25 \%)$ right ventricle-pulmonary artery $(R V P A)$ shunt patients underwent arch intervention. Seventy-two of 297 $(24 \%)$ modified Blalock-Taussig $(B T)$ shunt patients underwent arch intervention. Error bars contain $70 \%$ confidence intervals.

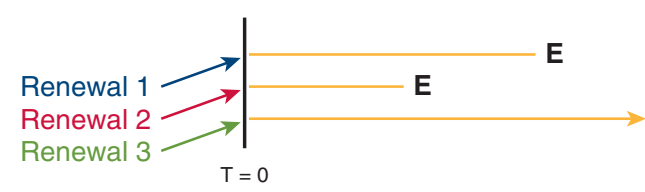

A

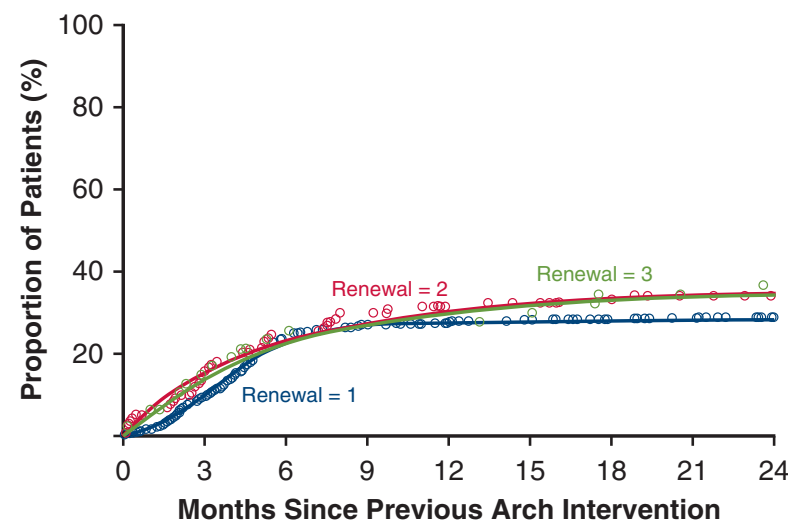

Number at Risk:

$\begin{array}{ccccc}593 & 352 & 301 & 280 & 262 \\ 146 & 100 & 84 & 78 & 72 \\ 49 & 34 & 34 & 30 & 28\end{array}$

B

FIGURE E2. Demonstration of modulated renewal procedure. A, A single patient's follow-up segmented for modulated renewal analysis. red lines represent follow up intervals segmented at arch intervention events (E). After each arch intervention, a renewal variable is updated as well as any relevant time-varying covariables. B, Solid lines indicate parametric models of the proportion of patients on each renewal curve. Colored circles indicate Kaplan-Meier estimates. All patients begin on the green renewal 1 curve and as they undergo arch interventions begin again at Time $=0$ on the renewal 2 curve and so on. Only curves for renewal 1,2, and 3 are shown because of small event numbers for subsequent renewal curves. 
TABLE E1. Participating institutions

\begin{tabular}{|c|c|}
\hline Institution & Location \\
\hline Ann \& Robert H. Lurie Children's Hospital & Chicago, Illinois \\
\hline Arnold Palmer Hospital for Children & Orlando, Florida \\
\hline Bronson Children's Hospital & Kalamazoo, Michigan \\
\hline Children's Hospital of Michigan & Detroit, Michigan \\
\hline Children's Hospital of Pittsburgh of UPMC & Pittsburgh, Pennsylvania \\
\hline Children's Hospital of Wisconsin & Wauwatosa, Wisconsin \\
\hline Children's Hospitals and Clinics of Minnesota & Minneapolis, Minnesota \\
\hline Children's Mercy & Kansas City, Missouri \\
\hline Children's National Health System & Washington, DC \\
\hline Children's of Alabama at UAB & Birmingham, Alabama \\
\hline CS Mott Children's Hospital & Ann Arbor, Michigan \\
\hline Doernbecher Children's Hospital & Portland, Oregon \\
\hline Hassenfeld Children's Hospital at NYU Langone & New York, New York \\
\hline Inova Children's Hospital & Falls Church, Virginia \\
\hline Intermountain Primary Children's Medical Center & Salt Lake City, Utah \\
\hline Johns Hopkins All Children's Hospital & St Petersburg, Florida \\
\hline Lucile Packard Children's Hospital Stanford & Palo Alto, California \\
\hline Nationwide Children's Hospital & Columbus, Ohio \\
\hline Nemours/Alfred I. DuPont Hospital for Children & Wilmington, Delaware \\
\hline Norton Children's Hospital & Louisville, Kentucky \\
\hline Penn State Health Milton S. Hershey Medical Center & Hershey, Pennsylvania \\
\hline Rady Children's Hospital & San Diego, California \\
\hline Riley Hospital for Children at Indiana University Health & Indianapolis, Indiana \\
\hline St Louis Children's Hospital & St Louis, Missouri \\
\hline The Hospital for Sick Children & Toronto, Ontario, Canada \\
\hline University of Florida Congenital Heart Center & Gainesville, Florida \\
\hline Yale New Haven Children's Hospital & New Haven, Connecticut \\
\hline
\end{tabular}


TABLE E2. Complete list of variables available for selection in the multivariable models

\begin{tabular}{|c|c|c|c|}
\hline Variable name & n (n missing) & $\%$ & $\begin{array}{c}\text { Median }(\mathrm{Q} 1-\mathrm{Q3}) \text { or } \\
\text { mean } \pm \text { STD }\end{array}$ \\
\hline Birth weight, kg & $529(64)$ & & $3.2 \pm 0.5$ \\
\hline Birth height, $\mathrm{cm}$ & $441(152)$ & & $49.5(47.0-51.0)$ \\
\hline Gestational age, wk & $546(47)$ & & $39(38-39)$ \\
\hline Sex & $593(0)$ & & \\
\hline Male & & $385(65)$ & \\
\hline Female & & $208(35)$ & \\
\hline Ethnicity & $476(117)$ & & \\
\hline Asian & & $11(2)$ & \\
\hline Black & & $39(8)$ & \\
\hline Hispanic & & $23(5)$ & \\
\hline Other & & $403(85)$ & \\
\hline Norwood weight, $\mathrm{kg}$ & $513(80)$ & & $3.1(2.9-3.5)$ \\
\hline Norwood height, $\mathrm{cm}$ & $365(228)$ & & $50.0(48.0-52.0)$ \\
\hline Norwood BSA, m² & $380(213)$ & & $0.20(0.19-0.22)$ \\
\hline Age at Norwood procedure, $\mathrm{d}$ & $593(0)$ & & $6(4-8)$ \\
\hline Date of Norwood procedure & $593(0)$ & & $\begin{array}{c}\text { June 29, } 2009 \\
\text { (July 2, 2007-March 29, 2012) }\end{array}$ \\
\hline Cardiopulmonary bypass time, minutes & $524(69)$ & & $148(122-175)$ \\
\hline Total circulatory arrest & $483(110)$ & $426(88)$ & \\
\hline Total circulatory arrest time, minutes & 379 (47) & & $11(5-37)$ \\
\hline Modified cerebral perfusion & $417(176)$ & $374(90)$ & \\
\hline Modified cerebral perfusion time, minutes & $306(68)$ & & $53(41-65)$ \\
\hline Proximal aortic anastomosis & $585(9)$ & & \\
\hline Classic & & $498(85)$ & \\
\hline Brawn & & $9(2)$ & \\
\hline Double barrel & & $59(10)$ & \\
\hline Modified & & $9(2)$ & \\
\hline Reimplantation & & $7(1)$ & \\
\hline Other & & $3(1)$ & \\
\hline Transection of proximal aorta & $571(22)$ & $62(11)$ & \\
\hline Patch augmentation type & $583(10)$ & & \\
\hline Modified bovine pericardium & & $21(4)$ & \\
\hline Homograft & & $535(92)$ & \\
\hline CorMatrix (CorMatrix Cardiovascular Inc, Sunnyvale, Calif) & & $3(1)$ & \\
\hline Pericardium & & $8(1)$ & \\
\hline GoreTex (W.L. Gore \& Associates Inc, Flagstaff, Ariz) & & $4(1)$ & \\
\hline None & & $12(2)$ & \\
\hline Shunt type & $593(0)$ & & \\
\hline RVPA conduit & & $296(50)$ & \\
\hline Modified BT shunt & & $294(50)$ & \\
\hline Central shunt & & $3(1)$ & \\
\hline Distal aortic anastomosis type & $565(28)$ & & \\
\hline Medial incision & & $395(70)$ & \\
\hline Interdigitated & & $78(14)$ & \\
\hline End to end & & $35(6)$ & \\
\hline End to side & & $5(1)$ & \\
\hline End to end with medial incision & & $52(9)$ & \\
\hline Coarctectomy (composite variable) & $565(28)$ & $170(30)$ & \\
\hline
\end{tabular}




\begin{tabular}{|c|c|c|c|}
\hline Variable name & n (n missing) & $\%$ & $\begin{array}{c}\text { Median }(Q 1-Q 3) \text { or } \\
\text { mean } \pm \text { STD }\end{array}$ \\
\hline Left atrial major axis length, $\mathrm{cm}$ & $429(164)$ & & $1.6(1.4-1.8)$ \\
\hline Left atrial minor axis length, $\mathrm{cm}$ & $429(164)$ & & $1.1(0.9-1.3)$ \\
\hline Left atrial area (4-chamber view), $\mathrm{cm}^{2}$ & $429(164)$ & & $1.6(1.3-2.1)$ \\
\hline Right atrial major axis length, $\mathrm{cm}$ & $430(163)$ & & $1.9(1.7-2.1)$ \\
\hline Right atrial minor axis length, $\mathrm{cm}$ & $430(163)$ & & $2.3 \pm 0.4$ \\
\hline Right atrial area (4-chamber view) & $430(163)$ & & $3.9(3.3-4.6)$ \\
\hline Inferior vena cava diameter, $\mathrm{cm}$ & $387(206)$ & & $0.7 \pm 0.1$ \\
\hline Abnormal pulmonary venous return & $458(135)$ & $11(2)$ & \\
\hline Mitral valve atresia & $458(135)$ & $180(39)$ & \\
\hline Mitral valve lateral diameter, $\mathrm{cm}$ & $440(153)$ & & $0.5(0.4-0.7)$ \\
\hline Mitral valve AP diameter, $\mathrm{cm}$ & $430(163)$ & & $0.5(0.3-0.7)$ \\
\hline Mitral valve area, $\mathrm{cm}^{2}$ & $430(163)$ & & $0.2(0.1-0.3)$ \\
\hline $\begin{array}{l}\text { Mitral valve abnormality } \\
\text { Supravalvular } \\
\text { Annular } \\
\text { Leaflets } \\
\text { Chords } \\
\text { Papillary muscle }\end{array}$ & $458(135)$ & $\begin{aligned} 431 & (94) \\
2 & (0.4) \\
423 & (92) \\
389 & (85) \\
19 & (4) \\
20 & (4)\end{aligned}$ & \\
\hline $\begin{array}{l}\text { Mitral valve regurgitation grade } \\
\text { None } \\
\text { Trivial } \\
\text { Mild } \\
\text { Moderate } \\
\text { Severe }\end{array}$ & $458(135)$ & $\begin{aligned} 330 & (72) \\
76 & (17) \\
44 & (10) \\
6 & (1) \\
2 & (0.4)\end{aligned}$ & \\
\hline $\begin{array}{l}\text { Mitral valve stenosis grade } \\
\text { None } \\
\text { Mild } \\
\text { Moderate } \\
\text { Severe } \\
\text { Atretic }\end{array}$ & $458(135)$ & $\begin{array}{c}39(9) \\
38(8) \\
43(9) \\
157(34) \\
180(39)\end{array}$ & \\
\hline Tricuspid valve lateral diameter, $\mathrm{cm}$ & $433(160)$ & & $1.3(1.2-1.4)$ \\
\hline Tricuspid valve AP diameter, $\mathrm{cm}$ & $419(174)$ & & $1.2(1.1-1.3)$ \\
\hline Tricuspid valve area, $\mathrm{cm}^{2}$ & $419(174)$ & & $1.2(1.0-1.4)$ \\
\hline $\begin{array}{l}\text { Tricuspid valve abnormality } \\
\text { Leaflets } \\
\text { Papillary muscle }\end{array}$ & $458(135)$ & $\begin{array}{l}4(1) \\
3(1) \\
1(0.2)\end{array}$ & \\
\hline $\begin{array}{l}\text { Tricuspid valve regurgitation grade } \\
\text { None } \\
\text { Trivial } \\
\text { Mild } \\
\text { Moderate } \\
\text { Severe }\end{array}$ & $457(136)$ & $\begin{array}{r}91(20) \\
195(43) \\
143(31) \\
25(5) \\
3(1)\end{array}$ & \\
\hline $\begin{array}{l}\text { Tricuspid valve regurgitation mechanism } \\
\text { Class I } \\
\text { Class II } \\
\text { Class IIIb } \\
\text { Not applicable }\end{array}$ & $458(135)$ & $\begin{aligned} 136 & (30) \\
1 & (0.2) \\
1 & (0.2) \\
320 & (70)\end{aligned}$ & \\
\hline
\end{tabular}


TABLE E2. Continued

\begin{tabular}{|c|c|c|c|}
\hline Variable name & n (n missing) & $\%$ & $\begin{array}{c}\text { Median }(Q 1-Q 3) \text { or } \\
\text { mean } \pm \text { STD }\end{array}$ \\
\hline Tricuspid valve stenosis grade & 458 (135) & & \\
\hline None & & 455 (99) & \\
\hline Mild & & $3(1)$ & \\
\hline Mitral valve:tricuspid valve ratio & $426(167)$ & & $0.1(0.1-0.2)$ \\
\hline Apex forming left ventricle & $458(135)$ & $34(7)$ & \\
\hline Hypoplastic left ventricle & $458(135)$ & $432(94)$ & \\
\hline Dominant left ventricle & $458(135)$ & $30(7)$ & \\
\hline Endocardial fibroelastosis grade & $443(150)$ & & \\
\hline 0 & & $222(50)$ & \\
\hline 1 & & $41(9)$ & \\
\hline 2 & & $112(25)$ & \\
\hline 3 & & $68(15)$ & \\
\hline Apex length, cm & $431(162)$ & & $3.0(2.8-3.2)$ \\
\hline Left ventricle end diastolic length, $\mathrm{cm}$ & 406 (187) & & $1.4(1.0-1.9)$ \\
\hline Left ventricle end systolic length, $\mathrm{cm}$ & 404 (189) & & $1.3(1.0-1.7)$ \\
\hline Left ventricle epicardial end diastolic length, $\mathrm{cm}$ & $431(162)$ & & $1.8(1.4-2.3)$ \\
\hline Left ventricle end diastolic area, $\mathrm{cm}^{2}$ & $382(211)$ & & $0.8(0.3-1.4)$ \\
\hline Left ventricle end systolic area, $\mathrm{cm}^{2}$ & $382(211)$ & & $0.7(0.2-1.1)$ \\
\hline Left ventricle end diastolic epicardial area, $\mathrm{cm}^{2}$ & $313(280)$ & & $2.7(1.9-3.9)$ \\
\hline Left ventricle end diastolic volume, $\mathrm{cm}^{3}$ & $380(213)$ & & $0.9(0.2-1.1)$ \\
\hline Left ventricle end systolic volume, $\mathrm{cm}^{3}$ & $380(213)$ & & $0.7(0.2-1.4)$ \\
\hline Left ventricle end diastolic epicardial volume, $\mathrm{cm}^{3}$ & $312(281)$ & & $4.5(2.6-7.3)$ \\
\hline Left ventricle mass (area length method), $\mathrm{g}$ & $312(281)$ & & $3.2(2.1-5.2)$ \\
\hline Left ventricle ejection fraction (area length method), $\%$ & $389(204)$ & & $13(0-31)$ \\
\hline Left ventricle end diastolic area (4-chamber view), $\mathrm{cm}^{2}$ & $438(155)$ & & $0.9(0.3-1.5)$ \\
\hline Left ventricle end systolic area (4-chamber view), $\mathrm{cm}^{2}$ & $382(211)$ & & $0.8(0.3-1.3)$ \\
\hline Left ventricle end diastolic epicardial area (4-chamber view), $\mathrm{cm}^{2}$ & $430(163)$ & & $2.0(0.9-3.2)$ \\
\hline Apex forming right ventricle & $458(135)$ & $443(97)$ & \\
\hline Right ventricle end diastolic basal diameter, $\mathrm{cm}$ & $431(162)$ & & $2.3(2.0-2.7)$ \\
\hline Right ventricle end diastolic midcavity diameter, $\mathrm{cm}$ & $431(162)$ & & $2.1(1.7-2.6)$ \\
\hline Right ventricle end diastolic length, $\mathrm{cm}$ & $431(162)$ & & $3.0(2.7-3.2)$ \\
\hline Right ventricle end diastolic area (4-chamber view), $\mathrm{cm}^{2}$ & $433(160)$ & & $6.5 \pm 1.8$ \\
\hline Right ventricle end systolic area (4-chamber view), $\mathrm{cm}^{2}$ & $433(160)$ & & $4.2(3.3-5.4)$ \\
\hline Right ventricle fractional area change (4-chamber view), $\%$ & $433(160)$ & & $33(27-40)$ \\
\hline Intracardiac left ventricular outflow tract obstruction & 449 (144) & $38(8)$ & \\
\hline Intracardiac left ventricular outflow tract obstruction type & 449 (144) & & \\
\hline Tunnel & & $29(6)$ & \\
\hline Fibromuscular ridge & & $5(1)$ & \\
\hline Aortic valve diameter, $\mathrm{cm}$ & $442(151)$ & & $0.3(0.2-0.4)$ \\
\hline Aortic valve atresia & $458(135)$ & $276(60)$ & \\
\hline Aortic valve stenosis grade & $457(136)$ & & \\
\hline None & & $14(3)$ & \\
\hline Mild & & $23(5)$ & \\
\hline Moderate & & $23(5)$ & \\
\hline
\end{tabular}


TABLE E2. Continued

\begin{tabular}{|c|c|c|c|}
\hline Variable name & n (n missing) & $\%$ & $\begin{array}{c}\text { Median }(Q 1-Q 3) \text { or } \\
\text { mean } \pm \text { STD }\end{array}$ \\
\hline Severe & & $121(26)$ & \\
\hline Atretic & & $276(60)$ & \\
\hline Aortic valve abnormality & 457 (136) & $444(97)$ & \\
\hline Aortic valve thickening & 449 (144) & $431(96)$ & \\
\hline Aortic valve regurgitation grade & $458(135)$ & & \\
\hline None & & $433(95)$ & \\
\hline Trivial & & $22(5)$ & \\
\hline Mild & & $3(1)$ & \\
\hline RV outflow tract obstruction & $458(135)$ & $0(0)$ & \\
\hline Pulmonary valve diameter, $\mathrm{cm}$ & $434(159)$ & & $1.0(0.9-1.1)$ \\
\hline Pulmonary valve stenosis grade & $458(135)$ & & \\
\hline None & & $456(99.6)$ & \\
\hline Mild & & $2(0.4)$ & \\
\hline Pulmonary valve regurgitation grade & 457 (136) & & \\
\hline None & & $195(43)$ & \\
\hline Trivial & & $252(55)$ & \\
\hline Mild & & $10(2)$ & \\
\hline Pulmonary valve peak velocity, $\mathrm{cm} / \mathrm{s}$ & $374(219)$ & & $100(84-113)$ \\
\hline Main pulmonary artery diameter, $\mathrm{cm}$ & $431(162)$ & & $1.1(1.0-1.2)$ \\
\hline Left pulmonary artery diameter, $\mathrm{cm}$ & $431(162)$ & & $0.5(0.4-0.5)$ \\
\hline Right pulmonary artery diameter, $\mathrm{cm}$ & $431(162)$ & & $0.5(0.4-0.5)$ \\
\hline Main pulmonary artery hypoplasia & $458(135)$ & $0(0)$ & \\
\hline Left pulmonary artery hypoplasia & $458(135)$ & $3(1)$ & \\
\hline Right pulmonary artery hypoplasia & $458(135)$ & $3(1)$ & \\
\hline Main pulmonary artery stenosis & $458(135)$ & $0(0)$ & \\
\hline Left pulmonary artery stenosis & $458(135)$ & $0(0)$ & \\
\hline Right pulmonary artery stenosis & $458(135)$ & $0(0)$ & \\
\hline Right aortic arch & $458(135)$ & $9(2)$ & \\
\hline Aortic arch hypoplasia & $454(139)$ & $427(94)$ & \\
\hline Coarctation of the aorta & $328(265)$ & $196(60)$ & \\
\hline Interrupted aortic arch & $458(135)$ & $11(2)$ & \\
\hline Aortic root diameter, $\mathrm{cm}$ & $434(159)$ & & $0.5(0.3-0.6)$ \\
\hline Sinotubular junction diameter, $\mathrm{cm}$ & $434(159)$ & & $0.3(0.2-0.5)$ \\
\hline Ascending aorta diameter, $\mathrm{cm}$ & $448(145)$ & & $0.3(0.2-0.5)$ \\
\hline Proximal transverse aorta diameter, $\mathrm{cm}$ & $432(161)$ & & $0.4 \pm 0.1$ \\
\hline Distal transverse aorta diameter, $\mathrm{cm}$ & $427(166)$ & & $0.4(0.4-0.5)$ \\
\hline Aortic isthmus diameter, $\mathrm{cm}$ & $411(182)$ & & $0.4(0.3-0.4)$ \\
\hline Descending aorta diameter, $\mathrm{cm}$ & $412(181)$ & & $0.6(0.6-0.7)$ \\
\hline Predominant flow in aortic arch & $455(138)$ & & \\
\hline Retrograde & & $407(89)$ & \\
\hline Antegrade & & $48(11)$ & \\
\hline Anomalous aortic origin of a coronary artery & $458(135)$ & $3(1)$ & \\
\hline Coronary sinusoids & $458(135)$ & $42(9)$ & \\
\hline Ventricular septal defect & $458(135)$ & $62(14)$ & \\
\hline
\end{tabular}


TABLE E2. Continued

\begin{tabular}{|c|c|c|c|}
\hline Variable name & n (n missing) & $\%$ & $\begin{array}{c}\text { Median (Q1-Q3) or } \\
\text { mean } \pm \text { STD }\end{array}$ \\
\hline Patent foramen ovale & $457(136)$ & $452(99)$ & \\
\hline Restrictive atrial septal defect & $439(154)$ & $225(51)$ & \\
\hline Decompressing vein & $458(135)$ & $10(2)$ & \\
\hline Atrial septal defect diameter, $\mathrm{cm}$ & $429(164)$ & & $0.4(0.3-0.5)$ \\
\hline Atrial septal defect peak velocity, $\mathrm{cm} / \mathrm{s}$ & $356(237)$ & & $135(100-170)$ \\
\hline Atrial septal defect mean velocity, $\mathrm{cm} / \mathrm{s}$ & $356(237)$ & & $85(62-114)$ \\
\hline Atrial septal defect mean gradient, $\mathrm{mm} \mathrm{Hg}$ & $359(234)$ & & $3(2-6)$ \\
\hline Patent ductus arteriosus & $458(135)$ & $458(100)$ & \\
\hline Shunt direction through ductus arteriosus & $458(135)$ & & \\
\hline Left to right & & $1(0.2)$ & \\
\hline Bidirectional & & $446(97)$ & \\
\hline Right to left & & $11(2)$ & \\
\hline Smallest diameter of ductus arteriosus, $\mathrm{cm}$ & 434 (159) & & $0.6(0.6-0.7)$ \\
\hline
\end{tabular}

Surgical arch reintervention*

Transcatheter arch reintervention*

Number of previous transcatheter arch reinterventions*

Number of previous surgical arch reinterventions*

Number of all previous arch reinterventions*

Degree of tricuspid regurgitation on any echocardiograph after the Norwood procedure $(0=$ mild or less, $1=$ moderate or more $) \dagger$

Degree of RV dysfunction on any echocardiograph after the Norwood procedure $(0=$ mild or less, $1=$ moderate or more $) \dagger$

Stage II palliation

Fontan procedure

Heart transplantation

Single ventricle to 2-ventricle crossover surgery

Tricuspid valve procedure

Q1-Q3, Quartile 1-quartile 3; STD, standard deviation; $B S A$, body surface area; $R V P A$, right ventricle-pulmonary artery; $B T$, Blalock-Taussig; $A P$, anteroposterior; $R V$, right ventricular. *Not included in first multivariable parametric model for freedom from arch reintervention because the first arch reintervention was treated as the end point in that analysis. †Binary variable that is updated with each echocardiograph after the Norwood procedure. 